\title{
Synthesis and Characterization of Multifunctional Branched Amphiphilic Peptide Bilayer Conjugated Gold Nanoparticles
}

\author{
Pavithra Natarajan, ${ }^{\dagger}$ Pinakin Sukthankar, ${ }^{\dagger} \perp^{\perp}$ Jessica Changstrom, ${ }^{\ddagger}$ Christopher S. Holland, ${ }^{\S}$ \\ Shannon Barry, ${ }^{\dagger}$ Wayne B. Hunter, ${ }^{\|}$Christopher M. Sorensen, ${ }^{\ddagger}$ and John M. Tomich, ${ }^{* \dagger \odot}$ \\ ${ }^{\dagger}$ Department of Biochemistry and Molecular Biophysics, Kansas State University, 141 Chalmers Hall, Manhattan, Kansas 66506, \\ United States \\ ${ }^{\ddagger}$ Department of Physics, Kansas State University, 116 Cardwell Hall, Manhattan, Kansas 66506, United States \\ ${ }^{\S}$ Maverick Biological, LLC, 2400 South Ocean Drive, Fort Pierce, Florida 34949, United States \\ "U.S. Horticultural Research Lab, USDA, ARS, 2001 South Rock Road, Fort Pierce, Florida 34945, United States
}

Supporting Information

\begin{abstract}
We provide strong chemical and biophysical evidence that documents that branched amphiphilic peptides, BAPs, known to assemble into spherical nanoassemblies in solution, do assemble as peptide-bilayer-delimited capsules. These nanoassemblies are termed branched amphiphilic peptide capsules (BAPCs). BAPCs are taken up by cells and accumulate in the perinuclear region to persist there without apparent degradation. BAPCs also entrap small proteins and solutes and stably encapsulate $\alpha$-particle-emitting radionuclides. We have devised a method utilizing thiol chemistry to conjugate these peptide sequences onto gold nanoparticles

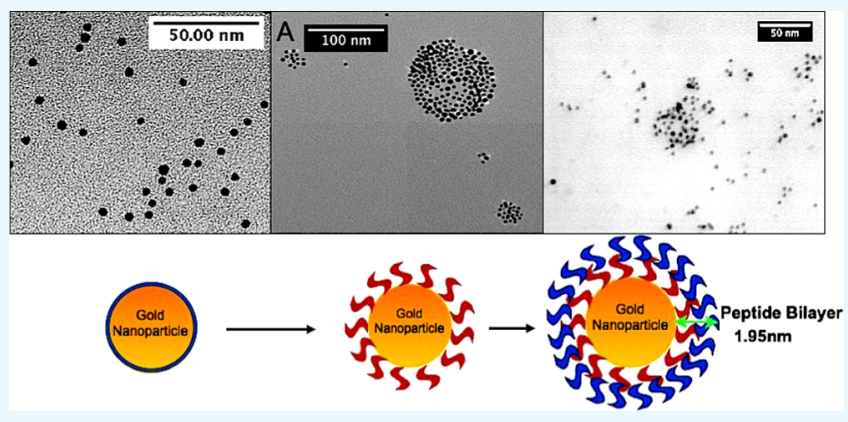
$(\leq 5 \mathrm{~nm})$ with the objective of demonstrating the assembly of these peptides into a bilayer. The peptides are initially assembled as a monolayer on the gold surface via interaction with cysteine residues on the peptide C-terminus in an organic solvent. The subsequent transition of these peptide-monolayerprotected gold nanoparticles to an aqueous solution in the presence of excess peptides led to the formation of the peptide bilayer on the gold surface. The approach was exploited further to produce bilayer-coated magnetic nanoparticles. The innovation described in this study provides a stable metallic nanoparticle-peptide conjugate system that will help to determine interactions of BAPs in a biological system, with relative ease, important for developing future applications such as simultaneous delivery and imaging of surface-bound molecules of interest.
\end{abstract}

\section{INTRODUCTION}

Branched amphiphilic peptides (BAPs), bis(Ac-FLIVI)-K- $\mathrm{K}_{4}$ -

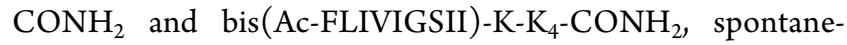
ously assemble at room temperature in an aqueous solution to form cationic capsules (vesicle-like spherical structures) called branched amphiphilic peptide capsules (BAPCs). The origin of BAPs can be traced to an internal peptide segment (underlined), derived from the pore-lining segment of the Ltype calcium channel (DPWNVFDFLIVIGSIIDVILSE). ${ }^{1}$ When chemically synthesized, the cleaved deprotected peptide forms insoluble mechanically resistant clumps upon dessication. $^{2}$ This property was ascribed to strong cohesive forces among the peptides and thus tested initially for peptide adhesion strength. The optimization of these sequences for solubility and functionality led to the creation of BAPs. ${ }^{1} \mathrm{We}$ have previously explored the effects of solvent, temperature, $\mathrm{pH}$, peptide composition, potentially destabilizing agents such as chaotropes, commercial proteases, and peptide ratios on the stability, structure, and assembly of BAPCs. ${ }^{2-5}$
Our studies show that the molecular architecture of BAPCs resembles liposomes, that is, bilayer-membrane-delimited vesicles. Few peptide amphiphiles self-assemble into stable bilayer membranes and/or form polymeric vesicles/capsules. ${ }^{6-8}$ Scanning electron microscopy/transmission electron microscopy (TEM) imaging data supported by coarse-grained modeling study suggested that BAPs form bilayer-delimited capsules. ${ }^{2,3}$ However, no direct experimental evidence has been generated to document the existence of the bilayer. In this study, we used nanoparticles (NPs) whose surface served as a scaffold to conjugate the inner leaflet. Excess peptide, delivered under controlled conditions, formed the outer leaflet of the bilayer. Self-assembly of the peptides into a bilayer on the nanoparticle surface was driven by the switch from an organic to an aqueous solvent, similar to the transition that leads to BAPC formation. ${ }^{1,2}$ This study reports the evidence that BAPs

Received: July 12, 2018

Accepted: August 28, 2018

Published: September 13, 2018 


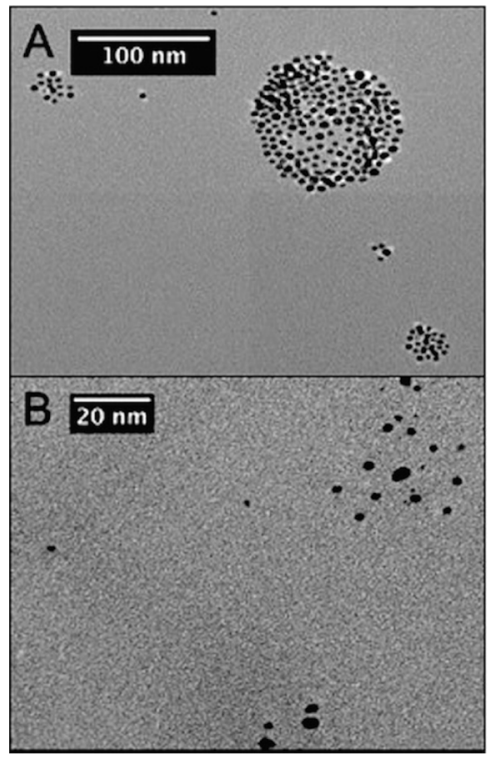

C

Peptide adducted to gold surface

(Ac-r- $\square$ FLIVIGSII) ${ }_{2}-$ KKKKKCys-CONH $r=\mathrm{H}$ $r=\mathrm{CN}$ in 4-cyanophenylalanine

\section{Outermost layer of peptide}

(Ac- LIVIGSII) ${ }_{2}-\mathrm{KKKKK}-\mathrm{CONH}_{2}$

$r=$ Phe

$r=\operatorname{Trp}$

OR

(Ac-FLIVI) $)_{2}$-KKKKK-r-CONH $r=\mathrm{Cys}$ with $\mathrm{CH}_{3} \mathrm{Hg}$

$r=$ no amino acid residue

Figure 1. Characterization of dodecanethiol-protected gold nanoparticle surfaces modified with BAPs. Transmission electron microscopy (TEM)

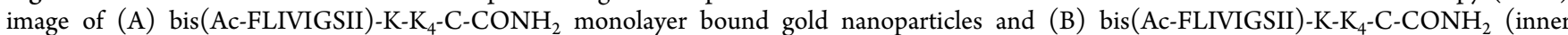
leaflet) and bis(Ac-FLIVI)-K- $\mathrm{K}_{4}-\mathrm{Cys}\left(\mathrm{Hg}-\mathrm{CH}_{3}\right)-\mathrm{CONH}_{2}$ (outer leaflet) bilayer bound gold nanoparticles in water. (C) Amino acid residue sequence of BAPs with modified versions synthesized for use in different experiments of this study, for conjugation to the gold surface via cysteine (left) and the peptides (right) added to form the second layer. The peptides were modified with fluorescent residues such as 4-cyanophenylalanine (PheCN) and tryptophan (W) as well as heavy metals like mercury $(\mathrm{Hg})$ to determine and characterize the peptide bilayer formation on gold nanoparticles. (D) Energy-dispersive X-ray (EDX) spectra showing the M shells of co-localized gold and mercury in BAP-AuNPs. The right panel shows the $10 \mathrm{~nm} \mathrm{Hg}$-labeled peptide bilayer Au particle that was scanned. The top-left panel shows the spectral counts recorded while scanning the surface of gold, while the bottom-left panel shows the spectral counts observed for mercury contained in the outer leaflet comprising solely bis(AcFLIVI)- $\mathrm{K}-\mathrm{K}_{4}-\mathrm{Cys}\left(\mathrm{Hg}-\mathrm{CH}_{3}\right)-\mathrm{CONH}_{2}$ peptide.

assemble as peptide bilayers in water and has led to the development of a gold nanoparticle (AuNP) conjugated multifunctional peptide bilayer complex, described for the first time to the best of our knowledge.

Gold nanoparticles (AuNPs) were chosen for their favorable properties that allow for the monitoring of bilayer formation. These properties include stability, inertness, ease of synthesis, surface functionalization, easy detection of surface alterations, and high electron density suitable for imaging. First, gold nanoparticles of specific sizes can be readily prepared following published procedures. Furthermore, their electronic property of localized surface plasmon resonance (LSPR) is a convenient preliminary indicator of surface functionalization. The observed LSPR wavelength $\left(\lambda_{\text {LSPR }}\right)$ is dependent on the shape, size, and distance between the adjacent nanoparticles and is affected by changes in the electronic environment. This provides for a visual indication since the color of AuNPs changes from orangish-red $(\sim 5-40 \mathrm{~nm})$ gradually to black $(\sim 100 \mathrm{~nm})$ as they begin to aggregate or bind to large molecules. Functionalized AuNPs are used to bind molecules of interest that cannot conjugate directly to gold. This approach has led to a variety of applications ranging from the fabrication of nanoelectronics ${ }^{9}$ to drug delivery, ${ }^{10}$ bioimaging, ${ }^{11}$ colorimetric assays, ${ }^{12}$ and detection of DNA ${ }^{13}$ and $^{\text {proteins. }}{ }^{14}$

Gold nanoparticles are typically synthesized by the reduction of gold chloride in the presence of a stabilizing capping reagent (i.e., the Brust-Schiffrin ${ }^{15}$ and Turkevich ${ }^{16}$ methods). Each of these techniques results in AuNPs of varying stability and sizes. Lin et al. ${ }^{17}$ described the facile synthesis of $5 \mathrm{~nm}$ gold nanoparticles stabilized by dodecanethiol in toluene. They used an inverse micelle system consisting of didodecyldime- thylammonium bromide/water/toluene followed by the addition of the digestive ripening agent dodecanethiol generating highly monodisperse AuNPs. These AuNPs were one of the two systems used for our study. The reduction of gold chloride (Turkevich method) by trisodium citrate in water yields $\sim 20 \mathrm{~nm}$ gold nanoparticles capped with sodium citrate molecules. Citrate stabilizes the AuNPs, keeping them well dispersed. Piella et al. ${ }^{18}$ have shown that stoichiometric amounts of tannic acid can help reduce the AuNP size to 3.5 nm known as seeds. Although AuNPs can be synthesized using certain peptides simultaneously for reduction and capping in a reducing buffer like $N$-(2-hydroxyethyl)piperazine- $N^{\prime}$-ethanesulfonic acid, ${ }^{19,20}$ obtaining monodispersed AuNPs using this approach is difficult. In this study, we used citrate-AuNPs synthesized using the method standardized by Piella et al. ${ }^{18}$ as our preferred green chemistry system for the BAP-bilayer conjugation.

AuNPs are most often functionalized with thiols since the AuNP surface atoms are electrophilic and have an affinity for nucleophiles like sulfur. Self-assembled monolayers on gold have been extensively studied and reviewed, ${ }^{21}$ but the nature of the $\mathrm{Au}$-thiol bond has not been determined unambiguously. However, a recent study using atomic force microscopy has shown that the $\mathrm{Au}-\mathrm{S}$ bond formed changes from coordinate to covalent as the $\mathrm{pH}$ of bond formation is transitioned from acidic to alkaline. ${ }^{22}$ The BAPs were modified with a cysteine residue on their oligolysine tail to facilitate their binding to AuNPs. Using an analogous approach, we prepared bilayercoated magnetic nanoparticles. We chose to employ magnetic beads (MNBs) modified with BAPs to assess nonspecific binding partners from serum and/or cytoplasm in future studies, given their ease of recovery from biological samples 

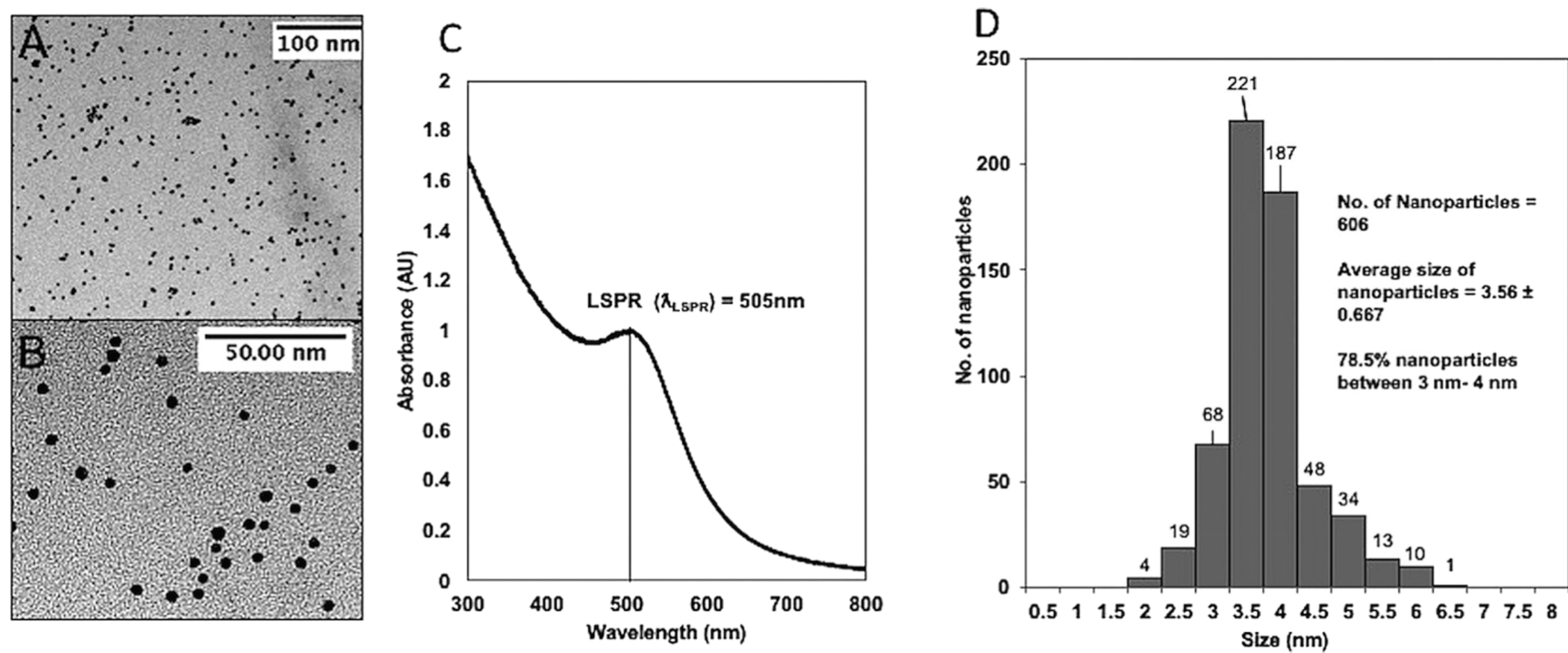

Figure 2. Characterization of aqueous, citrate-capped gold nanoparticles: (A, B) TEM images of citrate-AuNPs at two different magnifications. (C) Representative UV-vis spectra plotted using normalized absorbance values for the AuNPs between 300 and $800 \mathrm{~nm}$ with LSPR peak $\left(\lambda_{\text {LSPR }}\right)$ at 505 $\mathrm{nm}$. (D) Histogram depicts the size distribution of the AuNPs. The size was calculated for $\sim 600$ AuNPs in two different TEM image fields using ImageJ software. ${ }^{22}$ The histogram is unimodal showing a narrow distribution of AuNP sizes. The numbers on the top of each bar represent the number of AuNPs in each class. The average size of the AuNPs was calculated to be $3.56 \pm 0.667 \mathrm{~nm}$ with $78.5 \%$ of gold nanoparticles in 3-4 nm size range.

over conventional AuNPs. Besides, AuNPs are also known to quench fluorescence of molecules within $10 \mathrm{~nm}$ of their surface. $^{23}$ The MNBs also served as a control for the Forster resonance energy transfer (FRET) experiment for the determination of bilayer formation.

The magnetic nanoparticles generally made of ferromagnetic metals and the recently developed gold-coated nanoparticles with a magnetic core are widely used for biomedical applications. ${ }^{24-26}$ Similar to AuNPs, these can be functionalized for binding different molecules. Their magnetic property makes them useful in diagnostics as it helps in their rapid recovery from complex mixtures, separating them from unbound molecules. They are also used as magnetic resonance imaging agents, and studies are currently being carried out to use them for drug delivery by controlling them remotely with a magnetic device. ${ }^{24,25}$ The BAP-conjugated MNBs could thus find various biomedical applications.

BAPCs being highly cationic are readily taken up by eukaryotic cells and escape the late endosomes, leading to the successful release of surface-bound nucleic acids for genetic modulation. This has been demonstrated in prior studies where they have been successfully used in vivo to deliver an HPV-16 DNA vaccine in mice and siRNA orally in two insect species. $^{27,28}$ Thus, BAP-bilayer-conjugated AuNPs are great candidates for the simultaneous delivery of desired molecules and in vitro and in vivo imaging. The study presented has thus given us peptide-bilayer-conjugated metallic nanoparticle systems that can find applications in binding assays, imaging, and delivery.

\section{RESULTS AND DISCUSSION}

Generation of a Branched Amphiphilic Peptide Bilayer on Gold Nanoparticles in Toluene. Dodecanethiol-capped gold nanoparticles were initially used to prepare peptide-monolayer-adducted AuNPs (BAP monolayerAuNPs) suspended in toluene. ${ }^{17}$ The BAPs used for this preparation contained an additional cysteine residue at the $\mathrm{C}$ - terminus (bis(Ac-FLIVIGSII)-K- $\mathrm{K}_{4}-\mathrm{C}-\mathrm{CONH}_{2}$ ). These peptides were pretreated with ammonium hydroxide to deprotonate the lysyl residues, which renders the peptides fully soluble in toluene. The dodecanethiol-coated AuNPs were refluxed at $70{ }^{\circ} \mathrm{C}$ with excess peptides in toluene, facilitating cysteine-modified BAP monolayer self-assembly on the gold surface. Thiols with longer carbon chains displace the smaller carbon chain thiols and therefore the thiol-containing branched peptides formed a self-assembled peptide monolayer on AuNPs through this ligand substitution method. The subsequent transfer of the BAP monolayer-AuNPs into 1:1 trifluoroethanol (TFE) $/ \mathrm{H}_{2} \mathrm{O}$ gave a monodispersed colloidal solution of AuNPs with the branched N-terminal tails of the peptides' solvent exposed. Such colloidal suspensions in sealed containers have proven to be stable for greater than 6 months.

The BAP-monolayer-adducted AuNPs in 1:1 TFE/ $\mathrm{H}_{2} \mathrm{O}$ when dried on a TEM copper grid formed aggregates (Figure 1A). This is due to the increase in the $\mathrm{H}_{2} \mathrm{O}$ concentration as TFE evaporated, resulting in the association of the branched FLIVIGSII segments of the peptide generating the array of aggregates shown.

Water-soluble, peptide bilayer gold nanoparticles (BAPAuNPs) were generated by adding 1.1:1.0 excess of bis(AcFLIVI)-K-K $\mathrm{K}_{4}-\mathrm{CONH}_{2}$ to the bis(Ac-FLIVIGSII)-K-K $-\mathrm{C}$ $\mathrm{CONH}_{2}$-adducted AuNPs in the 1:1 TFE $/ \mathrm{H}_{2} \mathrm{O}$ mixture, followed by drying slowly to reduce the TFE concentration. The sample was subsequently fully dried, and then rehydrating yielded monodispersed BAP-AuNPs (Figure 1B). The presence of excess peptides in an aqueous environment drives the hydrophobic tails of the BAPs to interact with each other, thus leading to the formation of a BAP bilayer on the gold nanoparticles. The two parent peptide sequences, bis(AcFLIVI)-K-K $\mathrm{K}_{4}-\mathrm{CONH}_{2}$ and bis(Ac-FLIVIGSII)-K-K ${ }_{4}-\mathrm{CONH}_{2}$, were modified with fluorescent and heavy metal tags as required. The amino acid sequences of these peptides used for all experiments in this study have been summarized in Figure 1C. For the scanning transmission electron microscopy 
(STEM) studies, $30 \mathrm{~mol} \%$ bis(Ac-FLIVI)-K-K $\mathrm{K}_{4}-\mathrm{Cys}(\mathrm{Hg}$ $\left.\mathrm{CH}_{3}\right)-\mathrm{CONH}_{2}$ was added to the peptide monolayer conjugated to AuNPs. Energy-dispersive X-ray (EDX) analysis of a scanned single $10 \mathrm{~nm}$ BAP-AuNP showed overlapping signals for the gold- and the mercury-containing peptides in the outer leaflet, confirming its association with the inner leaflet (Figure 1D). While most BAP-AuNPs were $5 \mathrm{~nm}$ in diameter, a few $10 \mathrm{~nm}$ particles were observed. Analyses of larger sizes provided a better signal-to-noise ratio.

Aqueous Citrate-Capped Gold Nanoparticle Synthesis-A Green Chemistry Approach. Although the toluene-based system gave us the desired BAP-AuNPs, we wanted to adopt a green chemistry approach for synthesizing these nanoparticles. The basic scheme for the generation of the BAP-bilayer-coated gold nanoparticles using citrate-AuNPs as the starting material has been shown in Figure S1. The TEM images of the citrate-AuNPs synthesized using a standardized protocol showed well-dispersed AuNPs (Figure 2A,B). The UV-vis spectrum of the citrate-AuNPs gave a sharp LSPR spectral peak at $505 \mathrm{~nm}$ (Figure 2C), which is in agreement with the data published by Piella et al. ${ }^{18}$ Since sodium citrate molecules are small ligands, the LSPR peak is not significantly affected by the ligand on the surface and therefore one can consider that the plasmon resonance is characteristic of the gold core itself. The TEM images were used to measure the size of the nanoparticles using ImageJ software. ${ }^{29}$ The histogram (Figure 2D) plotted using the data obtained by measuring the size of $\sim 600$ citrate-AuNPs shows a fairly monodisperse population of AuNPs with an average size of $3.56 \mathrm{~nm}$ and standard deviation (SD) of $0.667 \mathrm{~nm}$. The number of nanoparticles synthesized in solution was determined using the absorbance at $\lambda_{\text {LSPR }}$ and extinction coefficient calculated using the eq 1

$$
\ln \varepsilon=3.32 \ln (d)+10.8
$$

where $d$ is the diameter of the spherical AuNPs in nm and $\varepsilon$ is the extinction coefficient of AuNP in $\mathrm{M}^{-1} \mathrm{~cm}^{-1}$. This equation was experimentally derived by Liu et al., ${ }^{30}$ where they examined three different types of capped AuNPs (citrate, oleylamine, and dodecanethiol capping) to standardize the extinction coefficient values for AuNPs of different sizes and capping agents. The extinction coefficient for $3.6 \mathrm{~nm}$ citrateAuNPs was calculated to be $3.44 \times 10^{6} \mathrm{M}^{-1} \mathrm{~cm}^{-1}$ using eq 1 . Using the Beer-Lambert law, the average number of AuNPs in solution was calculated to be $\sim 10^{13}$ AuNPs $/ \mathrm{mL}$.

Branched Amphiphilic Peptide Monolayer SelfAssembly on Citrate-Capped Gold Nanoparticles. The BAPs were subsequently conjugated to citrate-AuNPs to form a self-assembled peptide monolayer using the same chemistry used to prepare the BAP monolayer-AuNPs previously described, that is, ligand substitution by $\mathrm{Au}$-thiol bond formation but in $75 \%$ ethanol. The citrate molecules only weakly bind to the Au surface and are thus displaced easily. ${ }^{18}$ The BAPs were added to the citrate-AuNPs in $75 \%$ ethanol solution to prevent the self-assembly of the peptides into capsules. However, the citrate-AuNPs alone used as the control aggregated in the presence of ethanol. This was attributed to the presence of excess salts in the citrate-AuNPs solution that led to the formation of linear aggregates in ethanol. The linear aggregates have been thought to form because of the charge on the citrate molecules, leading to aggregation in a low-dielectric solvent like ethanol and increases with the increase in ethanol solvent concentration. ${ }^{31}$ This hindered the peptide's binding to
AuNPs. To prevent the aggregation of the AuNPs in ethanol so that the entire surface of the AuNPs was accessible for the binding of the peptides, the citrate-AuNPs were washed through a 10k molecular weight cut-off (MWCO). The removal of the excess salts such as the unreacted gold chloride and sodium citrate prevents the aggregation of the AuNPs in ethanolic solutions.

However, the aggregation of AuNPs was observed upon the addition of peptides to form the BAP monolayer even after the removal of excess salt. The UV-vis spectra showed a broad LSPR peak with high absorbance in the $600-800 \mathrm{~nm}$ region (Figure S2B), a characteristic of large AuNPs. This was confirmed by dynamic light scattering, where large aggregates $(100-2000 \mathrm{~nm})$ were detected (Figure S2A and Table S2). The observation suggested that the peptides while able to displace the citrate ions were not reacting efficiently with the gold surface, thus leaving much of the surface unprotected and prone to aggregation. The presence of hydrophobic trifluoroacetic acid (TFA) salts that were present as counterions associated with the C-terminal lysines were thought to hinder the binding of the peptide to the Au surface. To address this possibility, the TFA salts were replaced with chloride. The substitution was accomplished by multiple rounds of dilute $\mathrm{HCl}$ washes followed by freeze-drying, as previously reported in Andrushchenko et al. ${ }^{32}$ The process was monitored by NMR following the successive decreases in the fluorine $\left({ }^{19} \mathrm{~F}\right)$ signal intensity with each washing step. By the end of the fifth wash, no detectable fluorine signal was present, suggesting that most of the TFA salt had been exchanged with chloride (Figure S3). When these chloride-containing peptides were conjugated to AuNPs, we observed significant differences in the dispersion of peptide-adducted AuNPs (Figure S2B). The use of the peptides after chloride replacement eliminated the aggregation of AuNPs in water/alcohol mixture. For all subsequent experiments, we therefore chose to use the chloride counterion of peptides. In the case of the peptides used in the toluene-based system, the deprotonation of the lysyl residues using ammonium hydroxide followed by freeze-drying may have caused a loss of most of the TFA counterions. Besides, the hydrophobicity of toluene coupled with refluxing at high temperature could have helped in promoting the conjugation of peptides to AuNPs. The reaction of the chloride form of bis(Ac-FLIVIGSII)-K- $\mathrm{K}_{4}-\mathrm{C}-\mathrm{CONH}_{2}$ with the citrate-AuNPs yielded the desired product, as the binding of excess peptides to AuNPs was evidenced by a slight color change and a red shift in the gold plasmon wavelength. This change is indicative of a change in the electronic environment of the gold nanoparticles.

A titration experiment with the cysteine-containing peptide bis $\left(\mathrm{Ac}-\mathrm{F}_{\mathrm{CN}} \mathrm{LIVIGSII}\right)-\mathrm{K}-\mathrm{K}_{4}-\mathrm{C}-\mathrm{CONH}_{2}$ was conducted to ensure the complete coverage of the AuNP surface. A cyanophenylalanine $\left(\mathrm{Phe}_{\mathrm{CN}}\right)$ fluorescent tag was incorporated into the peptide sequence because it does not alter the secondary structure of the peptide and can also serve as a good donor for exciting tryptophan residues by FRET. ${ }^{33}$ Increasing

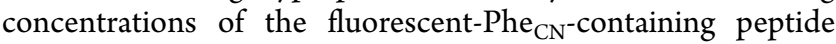
were tested, until no further increase in fluorescence was observed. The cyanophenylalanine group when excited at 240 $\mathrm{nm}$ has an emission maximum between 280 and $300 \mathrm{~nm}^{34}$ The concentration of bis(Ac- $\mathrm{F}_{\mathrm{CN}}$ LIVIGSII)-K-K $\mathrm{K}_{4}-\mathrm{C}-\mathrm{CONH}_{2}$ was varied from $1 \mu \mathrm{M}$ to $0.3 \mathrm{mM}$. The BAP monolayerAuNPs were prepared using the same protocol previously described. The fluorescence intensity of peptides bound to 
AuNPs did not increase beyond $0.2 \mathrm{mM}$ peptide concentration, and the AuNP surface appears to be saturated (Figure 3). Thus, $0.2 \mathrm{mM}$ peptide concentration was used subsequently for preparation of all BAP monolayer-AuNPs.

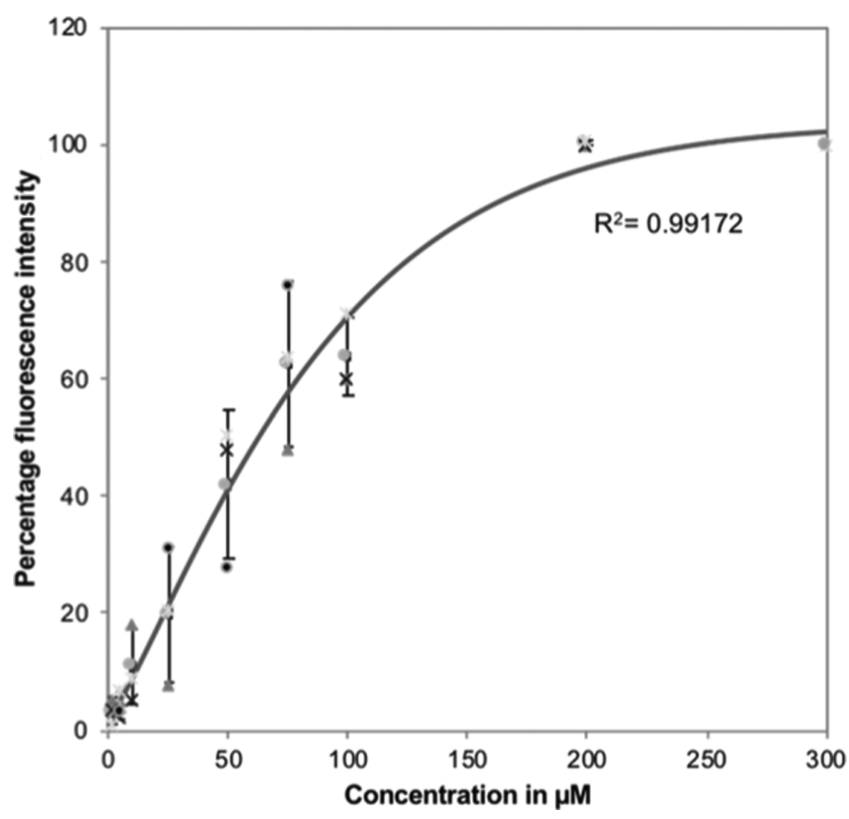

Figure 3. Fluorescence response for different concentrations of bis(Ac- $\left.\mathrm{F}_{\mathrm{CN}} \mathrm{LIVIGSII}\right)-\mathrm{K}-\mathrm{K}_{4}-\mathrm{C}-\mathrm{CONH}_{2}$ peptide added to gold nanoparticle surfaces. Different concentrations of bis(Ac- $\mathrm{F}_{\mathrm{CN}}$ LIVIGSII)-K$\mathrm{K}_{4}$-C-CONH${ }_{2}$ peptide, ranging from 2 to $300 \mu \mathrm{M}$, were added to gold nanoparticles to determine the maximum concentration at which the gold surface is saturated with the monolayer-forming peptide. The fluorescence intensity was normalized for different batches of the samples prepared as the percentage of fluorescence intensity of the AuNPs with maximum peptide concentration.

After the addition of the peptide, subsequent washes via centrifugation removed excess unbound peptides. The pelleted AuNPs were then redispersed in $100 \%$ TFE to ensure a monodispersed solution of AuNPs with the hydrophobic tails of the BAPs solvent exposed. As the dielectric constant of the solvent is increased by lowering the alcohol content by evaporation or dilution with water, the branched hydrophobic sequences find each other and form bilayers between adjacent AuNPs. Since the peptides are very small and lack electron density, they are invisible in the TEM images (Figure 4A,B). The TEM images of the BAP-monolayer-adducted AuNPs in water show a fairly uniform spacing among the nanoparticles. This gap represents the peptide bilayer. Using these TEM images, we calculated the width of the bilayer as the distance between two adjacent electron-dense AuNPs. The distance between 2 bis(Ac-FLIVIGSII)-K-K $\mathrm{K}_{4}$-C-CONH 2 -bound AuNPs, measured for $\sim 80$ pairs of AuNPs, was found to be $\sim 1.9 \mathrm{~nm}$ with a SD of $0.5 \mathrm{~nm}$. The bis(Ac-FLIVIGSII)-K-K ${ }_{4}$ $\mathrm{C}-\mathrm{CONH}_{2} \mathrm{BAP}$ bilayers are tightly packed with a packing density of 0.85 and are known to form smaller BAPCs as compared to those of bis(Ac-FLIVI)- $\mathrm{K}_{-}-\mathrm{K}_{4}-\mathrm{CONH}_{2}$-only bilayer with a packing density of $0.68 .^{35}$ Thus, when the distance between 2 AuNPs bound by bis(Ac-FLIVI)-K-K $\mathrm{K}_{4}-\mathrm{C}$ $\mathrm{CONH}_{2}$ peptides was measured, the average size of the bilayer was found to be $\sim 2.92 \mathrm{~nm}$ with a SD of $0.3 \mathrm{~nm}$ for 80 pairs. We could see a significant difference ( $p \leq 0.05$, Student's unpaired $t$-test) between the sizes of all bis(Ac-FLIVIGSII)-K-
$\mathrm{K}_{4}$-C-CONH$H_{2}$ and bis(Ac-FLIVI)-K- $\mathrm{K}_{4}-\mathrm{C}-\mathrm{CONH}_{2}$-only peptide bilayers, as expected on the basis of data from prior studies, providing further proof of peptide binding to gold nanoparticles.

Branched Amphiphilic Peptide Bilayer Formation on the Surface of Gold Nanoparticles. Peptide bilayers were assembled by adding a second layer of peptides to the BAP monolayer-AuNPs in TFE. The free peptide added to form the bilayer was added at the same concentration $(0.2 \mathrm{mM})$ used to saturate the surface of AuNPs to form the peptide monolayer. Theoretically, the second layer should require more peptides than that of the monolayer because of the increased surface area. This peptide concentration should be ideal to form the outer leaflet on most of the monolayer-coated AuNPs while simultaneously limiting the formation of higher number of BAPCs by excess, unbound free peptides in solution. The assembly of the peptides occurred as the water content of the solution was gradually increased until the organic solvent content is below $10 \%$, as described in Methods section. This increase in the dielectric value of the solvent drives the branched hydrophobic segments of the bis(AcFLIVIGSII)- $\mathrm{K}_{-} \mathrm{K}_{4}-\mathrm{CONH}_{2}$ peptides to associate with the hydrophobic peptide tails bound to the AuNPs, thus forming a bilayer. TEM images of the BAP-AuNPs (Figure 5A,B) show NPs that are fairly dispersed because of the cationic nature of the $\mathrm{BAP}-\mathrm{AuNP}$ surface, leading to the electrostatic repulsion of the individual particles. This was observed as a red shift in the LSPR spectral wavelength because of the change in the electronic environment of the AuNPs and also observed as a color change in the AuNP colloidal suspension solution. The LSPR spectral position shifted from $\sim 505 \mathrm{~nm}$ for citrateAuNPs to $\sim 514 \mathrm{~nm}$ for BAP-AuNPs in water. The UV-vis spectra from five separate reactions of similarly prepared BAPAuNPs showed an average LSPR peak at $514.78 \mathrm{~nm}$ with a SD of $2.81 \mathrm{~nm}$ (Figure 5C). Since LSPR spectral position is highly dependent on size, shape, and composition as well as solvent refractive index, an overlap in the UV-vis spectra indicates the reproducibility of protocol. A few aggregates of BAP monolayer-AuNPs appear to form a multiparticle system encapsulated by a peptide bilayer, as seen in TEM images. This suggests that some of the BAP monolayer-AuNPs were still able to interact as the water content was increased. These aggregates can be separated from the other monodispersed BAP-AuNPs by centrifugation at $\sim 75000 \mathrm{~g}$. The $\sim 7.5 \mathrm{~nm}$ BAP-AuNPs do not pellet out at this high speed.

The bilayer-modified BAP-AuNPs were vacuum-dried and easily resuspended in water as fairly monodispersed particles upon rehydration. On the other hand, dried BAP monolayerAuNPs could not be suspended in water without forming large aggregates. They precipitated out of solution to yield a colorless solution. However, dried BAP monolayer-AuNPs could be readily resuspended in $100 \%$ TFE. This difference in solvent preference of BAP monolayer-AuNPs with their exposed hydrophobic tails and bilayer-modified BAP-AuNPs with their solvent-exposed positively charged lysine tail indicates that the BAPs have assembled into a bilayer on the AuNP surface. The final yield of the BAP-AuNPs obtained is $\sim 25 \%$ of the starting gold nanoparticle concentration.

Thermogravimetric analyses (TGA) on both the monolayerand bilayer-modified bis(Ac-FLIVIGSII)-K-K $\mathrm{K}_{4}$-C-CONH${ }_{2} \mathrm{NPs}$ gave quantitative information on the number of peptides coupled to the AuNPs. Analyses to show interactions of different decomposition profiles due to a difference in the 

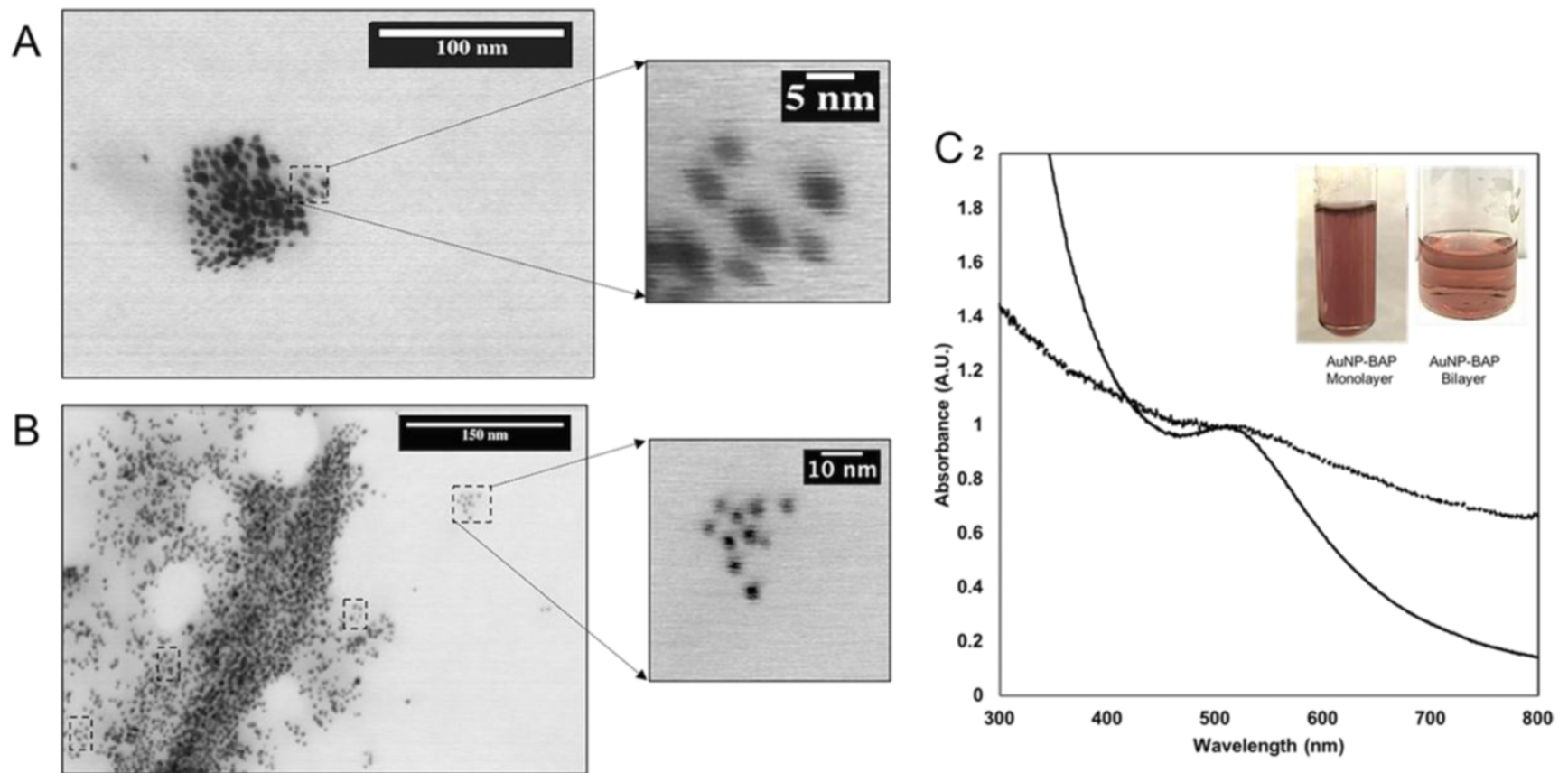

Figure 4. TEM and UV-vis spectral analysis of BAP-monolayer-adducted gold nanoparticles. (A) TEM image showing aggregates of gold nanoparticles modified with the bis(Ac-FLIVIGSII)-K- $\mathrm{K}_{4}-\mathrm{C}-\mathrm{CONH}_{2}$ peptide monolayer in water. The distance between two nanoparticles represents the thickness of the bis(Ac-FLIVIGSII)-K- $\mathrm{K}_{4}-\mathrm{CONH}_{2} \mathrm{BAP}$ bilayer and was measured for the uniformly spaced nanoparticles in clusters (e.g., dashed boxes). The average size of the bis(Ac-FLIVIGSII)- $\mathrm{K}_{-} \mathrm{K}_{4}-\mathrm{CONH}_{2}$ bilayer calculated for approximately 80 pairs of AuNPs is $1.95 \pm 0.5$ $\mathrm{nm}$. (B) TEM image showing aggregates of the bis(Ac-FLIVI)- $\mathrm{K}_{-} \mathrm{K}_{4}-\mathrm{C}-\mathrm{CONH}_{2}$-monolayer-adducted AuNPs in water. The average size of the bis(Ac-FLIVI)-K- $\mathrm{K}_{4}-\mathrm{CONH}_{2}$ bilayer calculated for $\sim 80$ pairs of AuNPs is $2.92 \pm 0.437 \mathrm{~nm}$. The average sizes of the bilayers were statistically determined using Student's unpaired $t$-test, $p \leq 0.05$. (C) UV-vis spectra of BAP monolayer-AuNP aggregates in water (gray line) and of BAPAuNPs in water (black line) for comparison. The inset shows the clear colloidal solution of monodispersed AuNP-BAPs (right) and the turbid AuNP-BAP monolayers in water (left).

nature of the bonds formed between the two peptide layers and the peptide-AuNPs were conducted.

In this study after determining the initial weight of the sample, the temperature was slowly increased from room temperature to $800{ }^{\circ} \mathrm{C}$. The amino acids decompose into $\mathrm{CO}_{2}$ and $\mathrm{H}_{2} \mathrm{O}$ over a particular temperature range, depending on their composition. As expected, the decomposition of the peptides was observed between 200 and $300{ }^{\circ} \mathrm{C}$ as a sharp decline in the weight of the sample. At the end of the heating cycle, the weight of the remaining sample was determined. The weight was attributed solely to the metallic nanoparticles since gold itself is not affected over this temperature range. The BAP monolayer-AuNPs (Figure $6 \mathrm{~A}$ ) showed $\sim 10 \%$ weight loss between 100 and $200{ }^{\circ} \mathrm{C}$, which was attributed to the decomposition of water absorbed by the peptides from the atmosphere. An approximate $40 \%$ weight loss was seen from 225 to $550{ }^{\circ} \mathrm{C}$ because of the decomposition of the BAPs. Two sharp weight-loss regions are observed in this range, which could be indicative of the loss of peptides binding the AuNPs with different strengths in the $225-400{ }^{\circ} \mathrm{C}$ and $400-550{ }^{\circ} \mathrm{C}$ regions. On the other hand, the bilayer-modified $\mathrm{BAP}-\mathrm{AuNPs}$ (Figure 6B) showed three distinct weight-loss regions. The sharp decrease $(\sim 30 \%)$ from 125 to $200{ }^{\circ} \mathrm{C}$ cannot be attributed to water decomposition alone but also to the loss of some of the outer leaflet peptides noncovalently bound to the BAP monolayer-AuNPs. The samples were dried completely, and $30 \%$ of the weight loss cannot be from water loss alone. BAPs are rich in lysine and isoleucine, which have been shown to start decomposing at a lower temperature, $\sim 120{ }^{\circ} \mathrm{C}$ for lysine ${ }^{36}$ and $\sim 180{ }^{\circ} \mathrm{C}$ for isoleucine, ${ }^{37}$ which could be contributing to a higher proportion weight loss in the 125$200{ }^{\circ} \mathrm{C}$.

The BAP monolayer-AuNPs TGA showed that $30 \%$ of the mass could be attributed to free AuNPs and 60\% to the mass of peptides. For the bilayer-modified BAP-AuNPs, $10 \%$ of the mass came from the AuNPs and $75 \%$ of the mass was from the bound peptides. This indicates that there is a stoichiometric difference for the number of peptides binding AuNPs in the monolayer and bilayer samples. The bilayer-modified BAPAuNPs show a different decomposition and mass loss profile compared to the BAP monolayer-AuNPs, providing further evidence that BAPs can be assembled into a bilayer on the surface of the gold nanoparticles.

To further confirm the formation of the bilayer, we conducted a FRET experiment. Phe $\mathrm{CN}_{\mathrm{CN}}$ and Trp are a FRET pair with Phe $\mathrm{CN}_{\mathrm{CN}}$ acting as the donor and Trp as the acceptor when irradiated at $240 \mathrm{~nm}$. The addition of the cyano group does not appear to perturb the structure of the assembly on the basis of circular dichroism (CD) analyses, as discussed later. In addition, designing the peptides such that the fluorescent molecules are placed at the peptide-peptide interface greatly improves the FRET efficiency and gives a better understanding of the distance among interacting moieties. ${ }^{33,38}$ On the basis of our modeling studies, these two residues should come in close proximity to one another when the bilayer forms. ${ }^{35}$ The bis(Ac- $\mathrm{F}_{\mathrm{CN}}$ LIVIGSII)-K-K $\mathrm{K}_{4}$-C-CONH 2 peptide used in the previous titration experiment was used for this FRET experiment.

The bis(Ac- $\mathrm{F}_{\mathrm{CN}}$ LIVIGSII)-K-K$-\mathrm{K}_{4}-\mathrm{C}-\mathrm{CONH}_{2}$ monolayer was formed on the AuNP surface by adding saturating levels of 

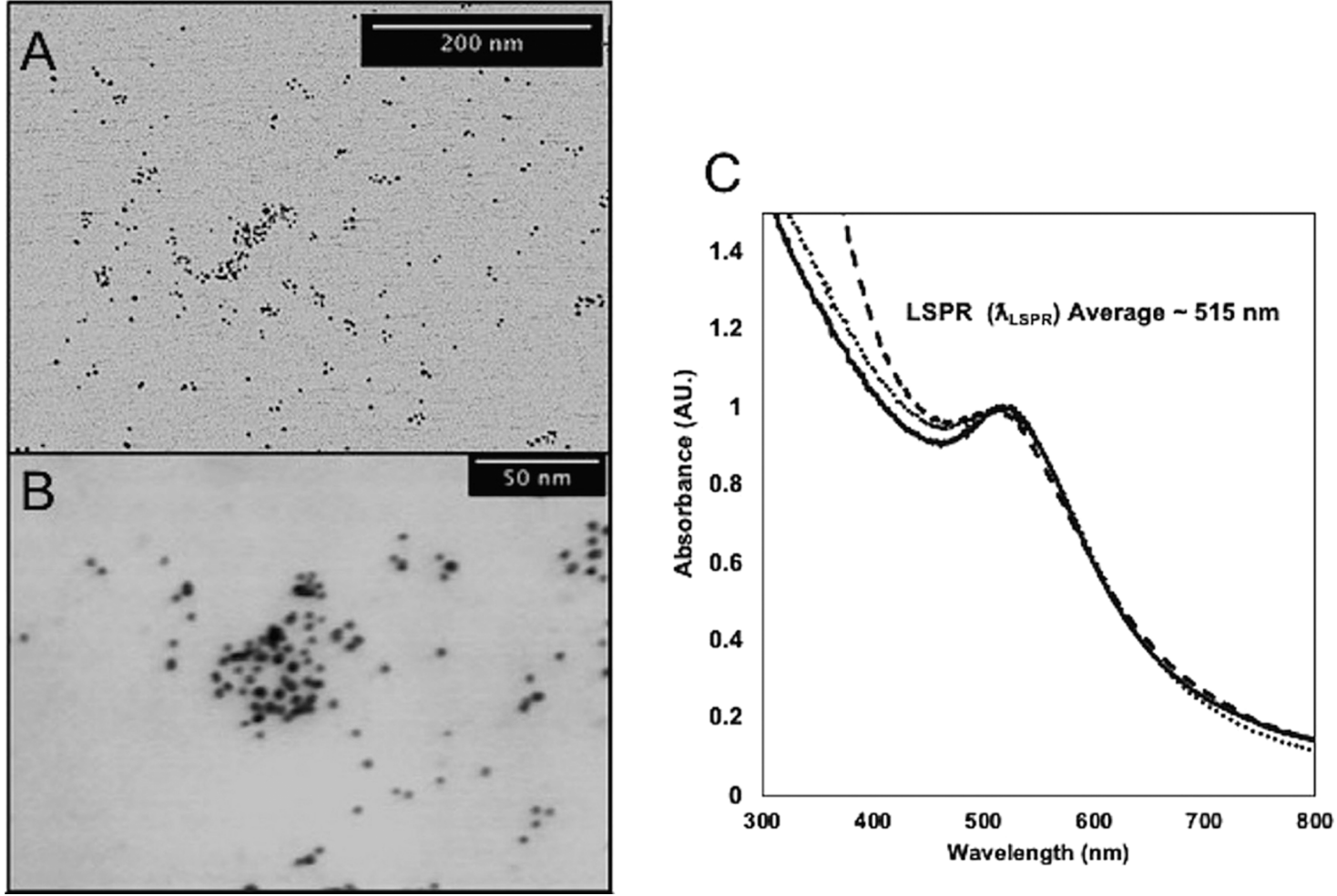

Figure 5. TEM images and UV-vis spectra of bis(Ac-FLIVIGSII)- $\mathrm{K}_{-} \mathrm{K}_{4}-\mathrm{CONH}_{2}$ BAP-bilayer-adducted gold nanoparticles. (A) Representative TEM image of the BAP-bilayer-adducted gold nanoparticles at a lower magnification capturing the well-dispersed AuNPs in a large image field. Few, if any, aggregates of the AuNPs are observed. (B) Relatively higher magnification TEM image of the BAP-AuNPs. (C) Overlapping UV-vis spectra of representative three different batches of BAP-AuNPs with normalized absorbance, showing a LSPR peak at $\sim 515 \mathrm{~nm}$.

peptides. Subsequently, bis(Ac-WLIVIGSII)-K-K$-\mathrm{K}_{4}-\mathrm{CONH}_{2}$ peptide was added, as previously described, to form the outer leaflet of the bilayer. After washing the bilayer-modified BAP-AuNPs with water through a 10k MWCO filter to remove any excess free peptides when they were excited at 240 $\mathrm{nm}$, we saw a shift in the emission peak to $360 \mathrm{~nm}$, characteristic of $\operatorname{Trp}$ emission, instead to $290 \mathrm{~nm}$, which is the emission from $\mathrm{Phe}_{\mathrm{CN}}$ (Figure $7 \mathrm{~A}$ ). The shift can be ascribed to the FRET phenomenon where the Trp accepts the photons emitted by $\mathrm{Phe}_{\mathrm{CN}}$ donor molecule at $290 \mathrm{~nm}$ on excitation at $240 \mathrm{~nm}$ and itself emits fluorescence at $360 \mathrm{~nm}$. Although the Phe ${ }_{\mathrm{CN}}$ fluorescence is not completely lost at 240 $\mathrm{nm}$, it is significantly decreased. The few aggregates observed in the $\mathrm{BAP}-\mathrm{AuNPs}$ solution might be contributing to the emission at $290 \mathrm{~nm}$ since $\mathrm{Phe}_{\mathrm{CN}}$ has a higher quantum yield of 0.11 and significantly higher molar absorptivity of $13500 \mathrm{M}^{-1}$ $\mathrm{cm}^{-1}$ at $240 \mathrm{~nm}$. The two emission peaks could also be indicative of the distance between the tightly packed, interdigitating BAP bilayers showing a complete overlap of the hydrophobic segments and hence a larger distance between the donor-acceptor on the opposite leaflets. Gold nanoparticles have strong absorption in the UV range; hence, it was not possible to determine the absorbance due to peptides alone accurately and therefore we could not calculate the FRET efficiency. Since they absorb in the UV range, we wanted to check whether gold nanoparticles themselves or with the nonfluorescent BAP bilayer bound to them have any influence on the fluorescence spectrum when excited at 240 $\mathrm{nm}$. No significant fluorescence signals for citrate-AuNPs alone (not shown) or BAP-AuNPs (nonfluorescent) in water were detected, as observed (Figure 7A). The gold nanoparticles exhibit some fluorescence, and the excitation/emission wave- lengths depend on the nature of the capping ligands, $\zeta$ potential, and size of the nanoparticles. ${ }^{39}$ However, the controls used helped us eliminate the possibility of interference by the AuNPs alone in the fluorescence emission spectral region used for analyses. The fluorescence emission profiles of bis(Ac- $\mathrm{F}_{\mathrm{CN}}$ LIVIGSII)-K-K $\mathrm{K}_{4}-\mathrm{C}-\mathrm{CONH}_{2}$ and bis(Ac-WLIVIG$\mathrm{SII})-\mathrm{K}_{-} \mathrm{K}_{4}-\mathrm{CONH}_{2}$ forming BAPCs in water were recorded. The fluorescence emission profiles of these BAPCs, as seen, do not give a complete shift in emission to $360 \mathrm{~nm}$ (Figure 7A). We see significantly high fluorescence emission from $\mathrm{Phe}_{\mathrm{CN}}$ and a slightly lower Trp fluorescence. Since there is no control over which two peptides come together in which leaflet and whether they are in proximity to themselves or the other residue, we cannot observe an enhanced FRET effect although we observe some. The bis(Ac- $\left.\mathrm{F}_{\mathrm{CN}} \mathrm{LIVIGSII}\right)-\mathrm{K}_{-} \mathrm{K}_{4}-\mathrm{C}-\mathrm{CONH}_{2}$ and bis(Ac-WLIVIGSII)-K-K $\mathrm{K}_{4}-\mathrm{CONH}_{2}$ equimolar mix in $100 \%$ TFE (monomeric peptides not forming capsules in solution) shows that bis(Ac- $\left.\mathrm{F}_{\mathrm{CN}} \mathrm{LIVIGSII}\right)-\mathrm{K}-\mathrm{K}_{4}-\mathrm{C}-\mathrm{CONH}_{2}$ emission predominates the spectrum because of its higher quantum yield even though bis(Ac-WLIVIGSII)-K-K $\mathrm{K}_{4}$ $\mathrm{CONH}_{2}$ by itself shows fluorescence when excited at 240 nm (not shown). ${ }^{34}$

We dispersed the BAP-AuNPs in $100 \%$ TFE, which should cause the outer leaflet of the bilayer on AuNPs to dissociate from the inner one because of the disruption of hydrophobic interactions between the peptides as well as the disruption of hydrogen bonding due to their transition back to a helical conformation. The fluorescence emission of the free peptides, once liberated, reverts back to $\sim 290 \mathrm{~nm}$ for $\mathrm{Phe}_{\mathrm{CN}}$. The same conditions would also have a disruptive effect on any free BAPCs that formed in solution for the reasons previously described. Newly freed peptide bis(Ac-WLIVIGSII)-K-K ${ }_{4}$ 


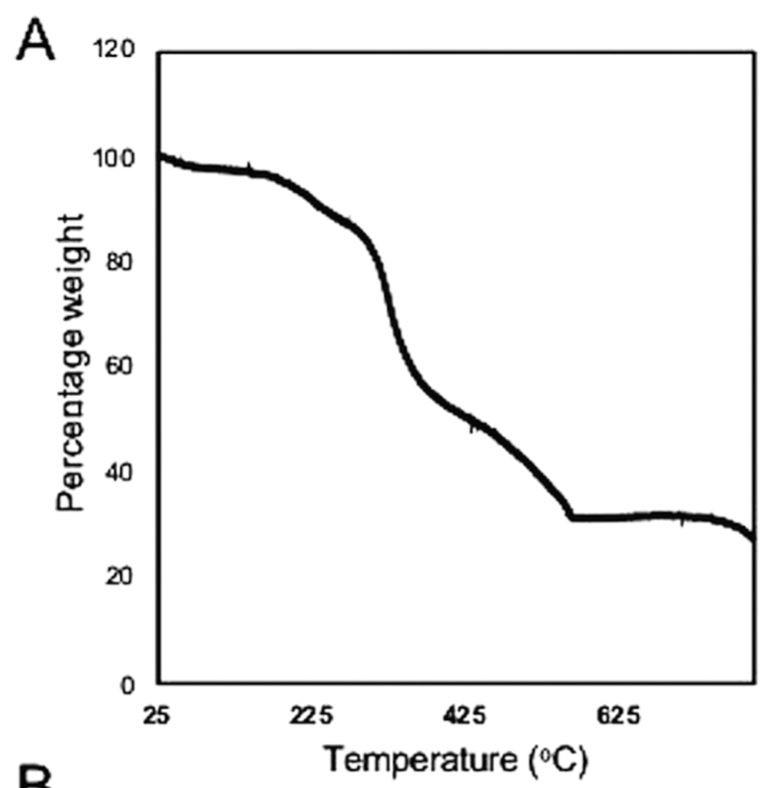

B

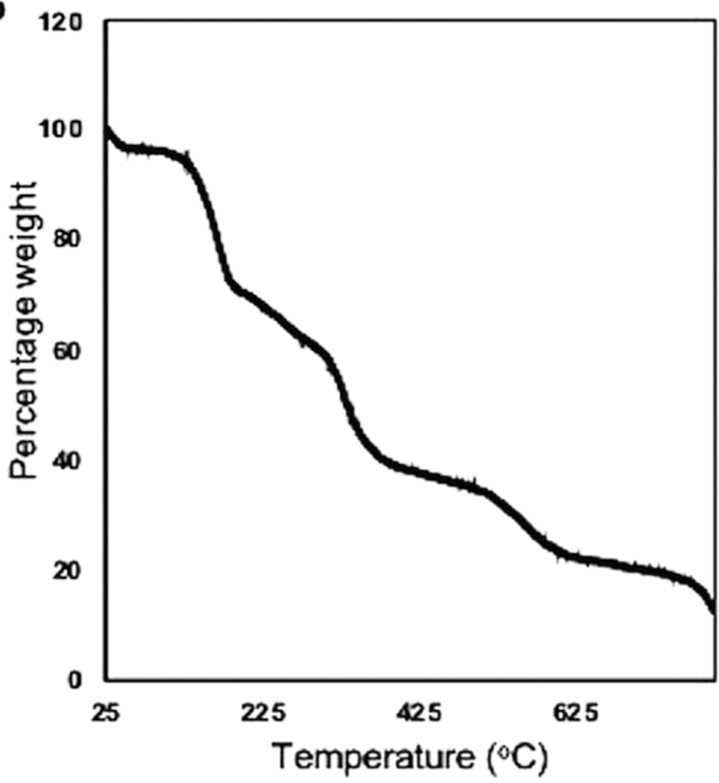

Figure 6. Thermogravimetric analysis (TGA) of gold nanoparticles modified with BAPs. The TGA curve represents the percentage of the starting weight for (A) BAP monolayer-AuNPs and (B) BAPAuNPs as the temperature increases from 25 to $800{ }^{\circ} \mathrm{C}$. The $30 \%$ weight loss observed between 125 and $225^{\circ} \mathrm{C}$ for the BAP-AuNPs is not observed for the BAP monolayer-AuNPs. It represents the weight loss due to the decomposition of the noncovalently bound outer leaflet of the peptide bilayer.

$\mathrm{CONH}_{2}$ from the BAPCs should again show one emission peak at $\sim 290 \mathrm{~nm}$. For this study, we observed that treating the BAP-AuNPs with $100 \%$ TFE shows only a modest drop in the fluorescence intensity at $360 \mathrm{~nm}$, with retention of the FRET effect (Figure 7A). The fluorescence profiles of these BAPAuNPs in $100 \%$ TFE somewhat resembled those of intact BAPCs in water. This result signifies that much of peptide bilayer bound to AuNPs was not disrupted by the solvent. We have observed this phenomenon previously for locked BAPCs described in Sukthankar et al., where the peptides adopt a structural configuration that makes them resistant to disruption by TFE. ${ }^{4}$ Therefore, when TFE is added, the peptide bilayer conjugated to the AuNPs does not dissociate, most probably

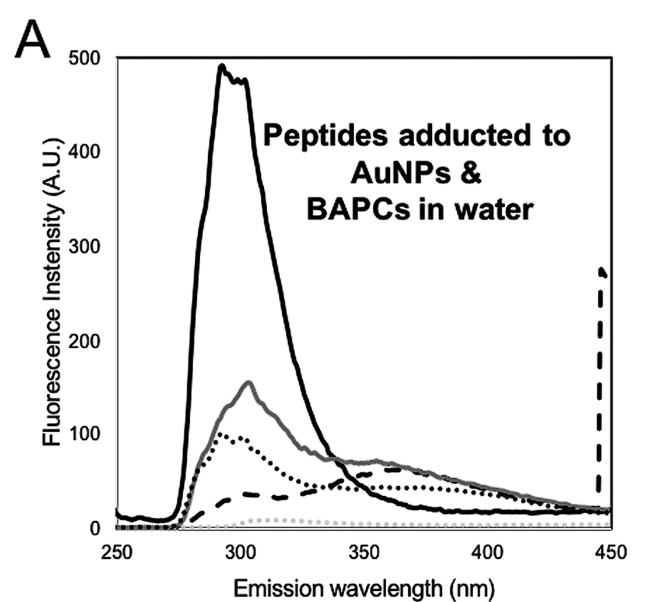

B

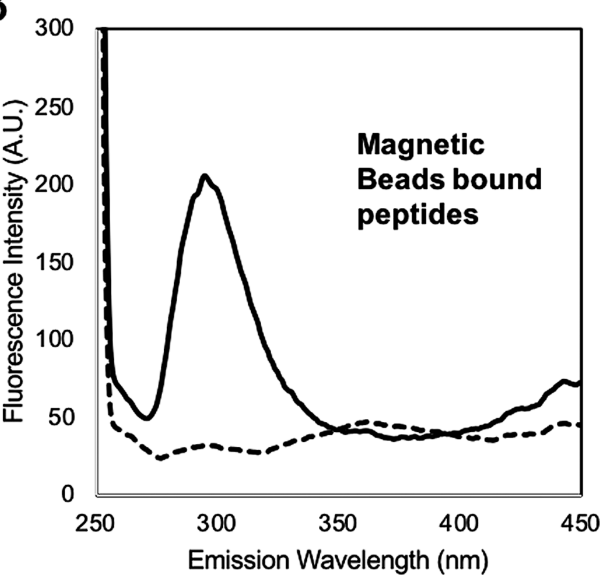

Figure 7. FRET demonstrating the formation of the BAP bilayer on gold nanoparticles. (A) Fluorescence profile for peptides binding to AuNPs. Bis(Ac- $\left.\mathrm{F}_{\mathrm{CN}} \mathrm{LIVIGSII}\right)-\mathrm{K}_{-} \mathrm{K}_{4}-\mathrm{C}-\mathrm{CONH}_{2}$-adducted gold nano-

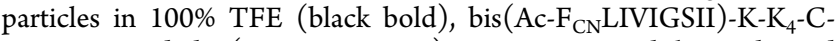
$\mathrm{CONH}_{2}$ and bis(Ac-WLIVIGSII)-K-K $\mathrm{K}_{4}-\mathrm{CONH}_{2}$ bilayer bound AuNPs (black dashed) in water and in 100\% TFE (black dotted). Nonfluorescent peptide bilayer bound AuNPs, that is, bis(AcFLIVIGSII)-K-K $\mathrm{K}_{4}-\mathrm{C}-\mathrm{CONH}_{2}$ and bis(Ac-FLIVIGSII)-K-K $\mathrm{K}_{4}-\mathrm{CONH}_{2}$ bound AuNPs (gray dotted) in water when excited at $240 \mathrm{~nm}$. BAPCs prepared with bis(Ac- $\left.\mathrm{F}_{\mathrm{CN}} \mathrm{LIVIGSII}\right)-\mathrm{K}_{-} \mathrm{K}_{4}-\mathrm{C}-\mathrm{CONH}_{2}$ and bis(AcWLIVIGSII)-K-K $\mathrm{K}_{4}-\mathrm{CONH}_{2}$ (gray bold). The binding of bis(AcWLIVIGSII)-K- $\mathrm{K}_{4}-\mathrm{CONH}_{2}$ peptide causes a FRET phenomenon, leading to the shift in fluorescence emission from $\sim 290 \mathrm{~nm}\left(\lambda_{\text {emission }}\right.$ for Phe $\left._{\mathrm{CN}}\right)$ to $\sim 360 \mathrm{~nm}\left(\lambda_{\text {emission }}\right.$ for Trp). (B) Magnetic nanobeads modified with maleimide groups binding with bis(Ac- $\mathrm{F}_{\mathrm{CN}}$ LIVIGSII)$\mathrm{K}-\mathrm{K}_{4}-\mathrm{C}-\mathrm{CONH}_{2}$ (black bold) in $75 \%$ TFE and with bis(Ac$\mathrm{F}_{\mathrm{CN}}$ LIVIGSII)-K-K $\mathrm{K}_{4}-\mathrm{C}-\mathrm{CONH}_{2}$ and bis(Ac-WLIVIGSII)-K-K $4^{-}$ $\mathrm{CONH}_{2}$ bilayer (black dashed) in deionized (DI) water.

because of the nature of the strong interactions between the peptides on the gold nanoparticles.

A conjugate was also made with commercially obtained magnetic nanobeads (MNBs), which were $50 \mathrm{~nm}$ in size and were surface-adducted with maleimide. The method uses maleimide chemistry to conjugate the cysteine of bis(Ac$\left.\mathrm{F}_{\mathrm{CN}} \mathrm{LIVIGSII}\right)-\mathrm{K}-\mathrm{K}_{4}-\mathrm{C}-\mathrm{CONH}_{2}$ to the surface and then forms the bilayer by adding excess bis(Ac-WLIVIGSII)-K-K $\mathrm{K}_{4}$ $\mathrm{CONH}_{2}$ as there is an increase in water concentration, as mentioned before. The MNBs with BAP monolayer alone show emission at $290 \mathrm{~nm}$ (Figure 7B), indicating the successful coupling of BAP to the surface. Addition of bis(AcWLIVIGSII)-K-K $\mathrm{K}_{4}-\mathrm{CONH}_{2}$ shows FRET effect similar to that of the BAP-AuNPs, where we see emissions at 290 and 
$360 \mathrm{~nm}$ (Figure 7B), indicating that the BAP bilayer was successfully formed. Thus, the MNBs act as a control here for bilayer formation on AuNPs. The BAP-MNBs showed a fluorescence profile similar to that of BAP-AuNPs separated from BAPCs in solution. The present BAPCs, if any, were separated from BAP-MNBs thoroughly using a magnetic separator. Thus, the FRET experiment provides strong evidence that the BAPs form a bilayer on AuNP and MNB surfaces in an aqueous solution.

Determination of Secondary Structure of Peptides Bound to Gold Nanoparticles. We wanted to compare the secondary structures of the BAPs when bound to the gold nanoparticles to those previously observed for BAPs free in solution. The tethered peptides that form the inner leaflet will not have the same ability to sample conformational space as those which are free in solution. Previously, it was established that bis(Ac-FLIVIGSII)-K-K $\mathrm{K}_{4}-\mathrm{CONH}_{2}$ BAPs assembled into capsules in water exhibit $\beta$-sheet secondary structure over a wide range of temperatures. ${ }^{4}$ Since it was established that a BAP bilayer successfully formed on the surface of AuNPs, determining the secondary structure of the inner leaflet as well as the bound bilayer was now possible. The BAP monolayerAuNPs in $100 \%$ TFE (Figure $8 \mathrm{~A}$ ) show a secondary structure intermediate between $\beta$-sheet and $\alpha$-helix with a broad peak ranging from $218 \mathrm{~nm}$ (characteristic of $\beta$-sheet) to $222 \mathrm{~nm}$ and a small peak at $208 \mathrm{~nm}$, both of which are characteristic of an $\alpha$-helix. The BAP-AuNPs in water (Figure 8A) show a strong $\beta$-sheet characteristic with a minimum peak at $218 \mathrm{~nm}$ similar to that of BAPCs in water. Citrate-AuNPs alone are not chiral and, as expected, do not exhibit any ellipticity, and bis(AcFLIVIGSII)-K-K $\mathrm{K}_{4}$-C-CONH${ }_{2}$ peptide alone in $75 \%$ TFE (Figure $8 \mathrm{~B}$ ) showed an $\alpha$-helical structure as monomeric peptides in TFE do.

With these results, we conclude that BAPs assemble to form a bilayer in water, leading to a transition in secondary structure from $\alpha$-helix to $\beta$-sheet because of intermolecular and intramolecular interactions between peptides of the two leaflets as they are transferred from a lower dielectric constant to an aqueous environment.

\section{CONCLUSIONS}

BAPs assemble into a bilayer when one leaflet at a time is added to gold nanoparticles, which serve as a substrate/scaffold for their formation. The self-assembly of BAPs as a bilayer is driven by the presence of water, causing the hydrophobic segments to interact with each other and thus shielding them from the hydrophilic solvent. Thus, BAPs are very similar in structure to phospholipids that self-assemble to form bilayerdelimited liposomes with significant advantages over their liposome counterparts. The gold nanoparticles capped with BAP bilayer are approximately $7.5 \mathrm{~nm}$ in size. These assemblies being smaller in size may serve as more-efficient delivery systems for surface-binding molecules like nucleic acids and proteins. Since BAPs are not degraded within cells because of their unique stability as an assembly, they may provide new capping agents that prevent toxicity caused by gold nanoparticle accumulation in vivo as bioaccumulation. ${ }^{40}$ Gold being electron dense is a good candidate for electron-beam-based imaging techniques like micro computed tomography scanning. ${ }^{41}$ Therefore, $\mathrm{BAP}-\mathrm{AuNPs}$ provide a system that can be used for imaging with targeted delivery simultaneously. The $\mathrm{BAP}-\mathrm{AuNPs}$ described here with their bilayer-forming nature
A

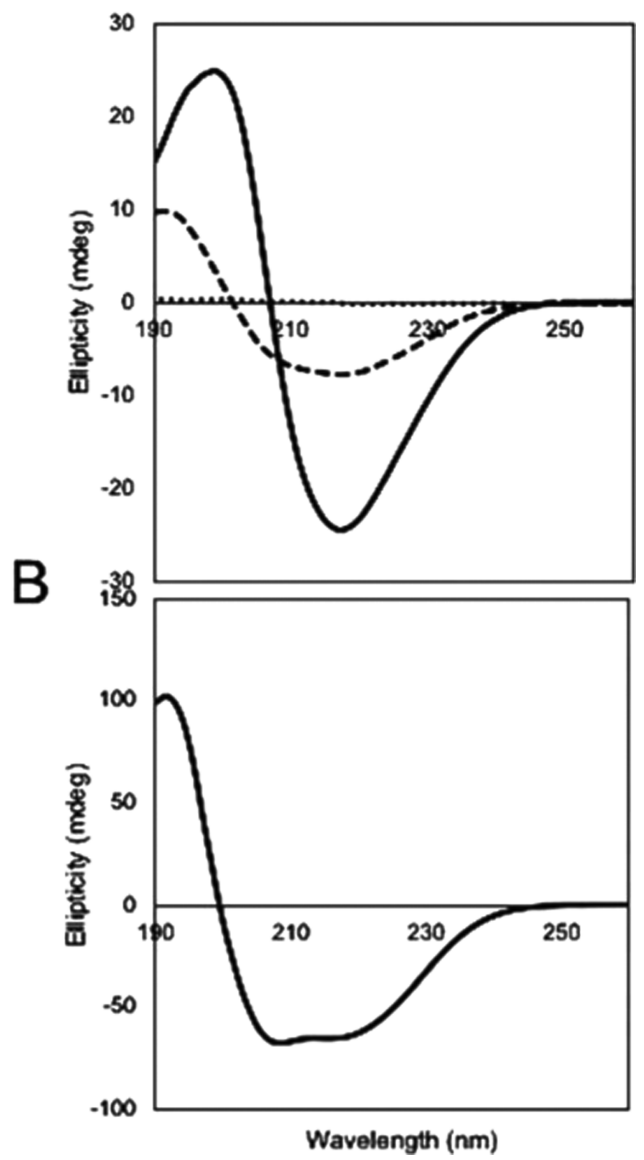

Figure 8. Circular dichroism spectra analysis of peptides bound to AuNPs. (A) BAP monolayer-AuNPs (dashed line) in 100\% TFE show slight $\beta$-characteristic as opposed to an all $\alpha$-helix structure observed in the free monomeric BAPs. The minimum peak is broad between 215 and $225 \mathrm{~nm}$, with minima at $222 \mathrm{~nm}$ and a slight peak at $208 \mathrm{~nm}$. The BAP-AuNPs (bold line) on the other hand show a strong $\beta$-sheet structure, with minima at $218 \mathrm{~nm}$, which is the structure adopted by BAPs when they form capsules in water. CitrateAuNPs alone were scanned (dotted line) as a control and, as expected, they do not show any ellipticity. (B) CD spectrum of bis(Ac-FLIVIGSII)-K- $\mathrm{K}_{4}-\mathrm{C}-\mathrm{CONH}_{2}$ monomeric peptides in $75 \%$ TFE showing a strong $\alpha$-helical characteristic.

can be applied to future studies in diagnostics as a delivery system in both in vitro and in vivo research.

\section{EXPERIMENTAL SECTION}

Solid-Phase Peptide Synthesis. The peptides were synthesized as previously published ${ }^{3}$ by an ABI 431 automated peptide synthesizer using Fmoc chemistry on $0.1 \mathrm{mmol}$ scale using CLEAR amide resin (Peptides International, Louisville, $\mathrm{KY}$ ). For the bis(Ac-FLIVIGSII)- $\mathrm{K}_{-} \mathrm{K}_{4}-\mathrm{CONH}_{2}$ peptides only, the initial amino acid was added manually and was allowed to react for $5 \mathrm{~min}$. Once this was completed, the resin was rinsed and capped with the acetyl capping cocktail to block any other unoccupied active sites on the resin. This is done to decrease the number of less-inaccessible sites on the resin, which usually ultimately results in a number of failed sequences at the end of the synthesis. This approach also spaces out the growing bis(Ac-FLIVIGSII)-K-K $-\mathrm{K}_{4}-\mathrm{CONH}_{2}$ chains, thereby reducing any interchain interactions during the synthesis that can 
cause irreversible peptide aggregation. The remainder of the synthesis was completed on the automated peptide synthesizer. The peptides were cleaved from the resin using a solution of 92\% TFA, 5\% thioanisole, and 2\% 1,2-ethanedithiol for $90 \mathrm{~min}$ at room temperature. The liquid was removed and poured into ice-cold diethyl ether. Three additional washes of the peptide precipitate were done with diethyl ether. The bis(Ac-FLIVI)$\mathrm{K}-\mathrm{K}_{4}-\mathrm{CONH}_{2}$ peptide was then suspended in distilled deionized water and lyophilized. The bis(Ac-FLIVIGSII)-K$\mathrm{K}_{4}-\mathrm{CONH}_{2}$ peptide was dried directly with diethyl either without suspending in water. The yield for the different peptide syntheses based on the initial resin substitution is between 30 and $40 \%$. This number does not accurately represent the actual yield because of the fact that we discard the less-accessible sites, as previously mentioned. On the basis of high-performance liquid chromatography analyses, the yield of the final peptide is closer to $75 \%$. The matrix-assisted laser desorption ionization time-of-flight mass spectrometry was used to ensure correct product formation with the peptide spotted in a DHB matrix (Sigma-Aldrich, St. Louis, MO) on a Bruker Ultraflex II instrument. The mass spectra for all peptides used in this study (prior to purification) are shown in Supporting Information (Figure S4).

Synthesis of BAP-AuNPs Using DodecanethiolCapped Gold Nanoparticles. Prior to the addition of the peptide to AuNPs in toluene (Fisher Scientific, Inc., NJ), the peptide was deprotonated by dissolving bis(Ac-FLIVIGSII)-K$\mathrm{K}_{4}-\mathrm{C}-\mathrm{CONH}_{2}$ peptide in water and adjusting the $\mathrm{pH}$ to 14 with ammonium hydroxide (Fisher Scientific, Inc., NJ), incubating it for $1 \mathrm{~h}$, and then drying it in vacuo. This allows the peptide to easily dissolve in toluene. A 2-fold excess of peptide was added to the dodecanethiol-capped AuNPs in toluene and then refluxed under argon for $90 \mathrm{~min}$, leading to the substitution of dodecanethiol with bis(Ac-FLIVIGSII)-K$\mathrm{K}_{4}-\mathrm{C}-\mathrm{CONH}_{2}$ peptide. This BAP-monolayer-conjugated AuNPs in toluene were dried in vacuum and redispersed in $50 \%$ trifluoroethanol in water (Sigma-Aldrich, Inc., Wiscon$\sin$ ). The excess unreacted peptide was removed by filtering it through a $30 \mathrm{kDa}$ MWCO Amicon, Ultra $0.5 \mathrm{~mL}$ filter (Merck, Millipore Inc., Burlington, MA). A 1.1:1.0 excess of bis(AcFLIVI)-K-K $\mathrm{K}_{4}-\mathrm{CONH}_{2}$ /bis(Ac-FLIVIGSII)-K-K $\mathrm{K}_{4}-\mathrm{CONH}_{2}$ peptide was added to the BAP-monolayer-conjugated AuNPs with thorough mixing and was then dried. For STEM, we used 30 mol \% bis(Ac-FLIVI)-K- $\mathrm{K}_{4}-\mathrm{C}\left(\mathrm{CH}_{3} \mathrm{Hg}\right)-\mathrm{CONH}_{2}$ instead. The rehydration of this mix under mild acidic conditions gives BAP-bilayer-modified AuNPs.

Replacement of Trifluoroacetic Acetate (TFA Salt) Peptide Counterion with Chloride. The TFA-salt replacement was carried out by the acid substitution protocol mentioned in Andrushchenko et al. ${ }^{32}$ The peptides were solubilized in a 1:1 ethanol/water solution to prevent selfassembly into capsules. Hydrochloric acid, $1 \mathrm{mM}$, (Fisher Scientific, Inc., NJ) was added with thorough mixing to the peptide solution. The peptide solution was then frozen at -80 ${ }^{\circ} \mathrm{C}$, followed by lyophilization using a Lab Conco (Free Zone $2.5 \mathrm{~L}$, benchtop) freeze-dryer and Savant concentrator. This process was repeated for an additional four times with $100 \mu \mathrm{M}$ $\mathrm{HCl}$. The complete dissolution of peptides was ensured to ensure efficient reaction. The efficiency of TFA-salt displacement from peptides by $\mathrm{HCl}$ was determined by onedimensional fluorine $\left({ }^{19} \mathrm{~F}\right)$ NMR scans of peptides after every wash.
Synthesis of Citrate-Capped Gold Nanoparticles. The citrate-capped gold nanoparticles were prepared as described in Piella et al. ${ }^{18}$ For the preparation of $3.5 \mathrm{~nm}$ gold nanoparticles, $100 \mathrm{~mL}$ of freshly prepared $2.2 \mathrm{mM}$ sodium citrate (Fisher Scientific, Inc., NJ) solution in deionizeddistilled (DDI) water and $668 \mu \mathrm{L}$ of $150 \mathrm{mM}$ potassium carbonate (Fisher Scientific, Inc., NJ) were refluxed at $70^{\circ} \mathrm{C}$ in a round-bottomed flask under vigorous stirring on a Corning magnetic heat-stir plate. $66.8 \mu \mathrm{L}$ of freshly prepared $2.5 \mathrm{mM}$ tannic acid (Sigma-Aldrich, Inc., WI) was added, followed by $668 \mu \mathrm{L}$ of $25 \mathrm{mM}$ gold chloride $\left(\mathrm{HAuCl}_{4}\right)$ (Sigma-Aldrich, Inc., WI) under vigorous stirring. The color of the solution turned from brownish-black to orangish-red in less than a minute. The solution was heated for an additional $20 \mathrm{~min}$ to ensure complete reduction of $\mathrm{HAuCl}_{4}$. On cooling, the citratecapped gold nanoparticles were washed using $20 \mathrm{~mL}, 10 \mathrm{k}$ MWCO-Omega filters (Pall Corporation Centrifugal Devices) to remove excess salts. The concentrated gold nanoparticles free of excess salts were diluted back to their original concentration with DDI water. The UV-vis spectrum was recorded from 200 to $800 \mathrm{~nm}$ at the rate of $300 \mathrm{~nm} / \mathrm{min}$ and $0.5 \mathrm{~nm}$ data interval with baseline correction using water as the blank on Cary 50-Bio UV-Vis Spectrophotometer (Varian Inc., Palo Alto, CA).

Modification of Citrate-Capped Gold Nanoparticles with a Peptide Bilayer. The concentration of the peptide required to completely cover the surface of the gold nanoparticles was theoretically calculated to be $2 \mu \mathrm{M}$ for a solution containing $\sim 10^{13}$ gold nanoparticles of average size $3.6 \mathrm{~nm}$. Prior to the addition of the peptides, the nanoparticles were sonicated using a FS20 (Fisher Scientific, Inc., NJ) water bath sonicator so as to evenly disperse the nanoparticles in solution. This breaks any small clusters of nanoparticles and therefore increases the surface area accessible for peptide binding. $0.2 \mathrm{mM}$ bis(Ac-FLIVIGSII)-K-K $\mathrm{K}_{4}-\mathrm{C}-\mathrm{CONH}_{2}$ peptide (concentration was calculated using Phe absorbance at 257.5 $\mathrm{nm}$ with $\varepsilon=195 \mathrm{M}^{-1} \mathrm{~cm}^{-1}$ ) in $75 \%$ ethanol was added to the citrate-capped gold nanoparticles. The organic solvent content was maintained at $75 \%$ to prevent self-assembly of the free peptides and to prevent the AuNP-bound peptides from aggregating because of hydrophobic tail interactions. The AuNP-bis(Ac-FLIVIGSII)-K-K $\mathrm{K}_{4}-\mathrm{C}-\mathrm{CONH}_{2}$ peptide mix was incubated for $1 \mathrm{~h}$ at room temperature with constant mixing to ensure maximum binding and coverage of the nanoparticle surface. The bis(Ac-FLIVIGSII)-K-K $\mathrm{K}_{4}-\mathrm{C}-\mathrm{CONH}_{2}$-adducted AuNPs were washed by centrifugation at 37000 relative centrifugal field for $30 \mathrm{~min}$ in poly(tetrafluoroethylene) centrifuge tubes (Thermo Scientific, Nalgene Products Inc., $\mathrm{NY}$ ) on a JA-20 rotor in a model J2-21 Beckman centrifuge. The AuNPs were washed three times, and after every wash, the AuNPs were suspended in $100 \%$ ethanol. After the third wash, the AuNP-bis(Ac-FLIVIGSII)-K- $\mathrm{K}_{4}-\mathrm{C}-\mathrm{CONH}_{2}$ was suspended in a minimal amount of $100 \%$ TFE. The (bis(Ac-FLIVIGSII)$\left.\mathrm{K}-\mathrm{K}_{4}-\mathrm{CONH}_{2}\right)$ peptide $(0.2 \mathrm{mM})$ was added to the AuNPbis(Ac-FLIVIGSII)-K-K $-\mathrm{K}_{4}-\mathrm{C}-\mathrm{CONH}_{2}$ monolayer in TFE and mixed well. Excess, that is, 25 times more, water was added to this TFE solution gradually so that the organic solvent concentration is below $10 \%$ and incubated for 30 min with constant mixing. The AuNP-BAPs were then washed through 10k MWCO filters to remove any excess unbound peptides and were redispersed in minimal DDW to obtain a concentrated AuNP-BAP solution. 
Transmission Electron Microscopy and Energy-Dispersive X-ray (EDX) Spectrometry. The sample $(20 \mu \mathrm{L})$ was placed onto a 200-mesh Formvar-coated grid for $10 \mathrm{~min}$, and the excess sample was wicked off using a filter paper. Samples were given $30 \mathrm{~min}$ to dry completely prior to visualization. The energy of the X-ray emitted by the heavy metals, that is, gold and mercury, was detected using an EDX detector linked to the Hitachi S-4800 (Hitachi high Tech, Inc., Pleasanton, CA) STEM instrument.

FRET Experiment. The gold nanoparticles with the requisite peptide bilayer, that is, bis(Ac- $\mathrm{F}_{\mathrm{CN}}$ LIVIGSII)-K-K $\mathrm{K}_{4}-$ $\mathrm{C}-\mathrm{CONH}_{2}$ and bis(Ac-WLIVIGSII)- $\mathrm{K}_{-} \mathrm{K}_{4}-\mathrm{CONH}_{2}$ bilayer, were prepared in the same way as the gold nanoparticles with the BAP bilayer, as mentioned above. The MNBs were obtained from Ocean Nanotech (San Diego, CA). Bis(Ac$\mathrm{F}_{\mathrm{CN}}$ LIVIGSII)-K-K$-\mathrm{K}_{4}-\mathrm{C}-\mathrm{CONH}_{2}$ was covalently linked to the maleimide on the functionalized $\mathrm{MNBs}$ in $75 \%$ ethanol solution by adjusting the $\mathrm{pH}$ to 7.4 using $0.1 \mathrm{~N} \mathrm{NaOH}$. The MNBs were washed on an Invitrogen bead separator (Invitrogen Corp., Carlsband, CA), and the bilayer was formed by adding excess bis(Ac-WLIVIGSII)-K- $\mathrm{K}_{4}-\mathrm{CONH}_{2}$ and dispersing it in water. The MNBs with the peptide bilayer were washed three times by giving sufficient time for the beads to separate out. The bis(Ac-FLIVIGSII)-K-K $-\mathrm{C}-\mathrm{CONH}_{2}$ modified at Phe with $\mathrm{CN}$ were excited at $240 \mathrm{~nm}$, and the emission was recorded as a scan from 250 to $500 \mathrm{~nm}$ on Varian Cary Eclipse Fluorescence Spectrophotometer (Varian Inc., Palo Alto, CA) at a scan rate of $600 \mathrm{~nm} / \mathrm{min}$ and data interval of $1 \mathrm{~nm}$. The slit was adjusted between 5 and 10, as per the fluorescence intensity obtained from the sample to obtain significant fluorescence intensity reading. The samples were placed in a quartz cuvette with a path length of $0.3 \mathrm{~cm}$ (Starna Cells Inc., Atascadero, CA).

To test the effect of $100 \%$ TFE on the dissociation of the outer peptide leaflet on BAP-bilayer-conjugated AuNPs, they were dried in vacuo, as previously described. Neat TFE was added to them and then thoroughly mixed to completely resuspend the AuNPs. They were incubated at room temperature for $30 \mathrm{~min}$ and were washed using a $30 \mathrm{k}$ MWCO spin filter to remove any peptides separated from the bilayer. The NPs were again resuspended in the same volume of $100 \%$ TFE to re-establish the initial concentration. The fluorescence spectrum was then collected by excitation at $240 \mathrm{~nm}$, a slit of 5, and scanned for emission wavelengths between 250 and $450 \mathrm{~nm}$.

CD Spectroscopy Measurements. CD data was collected on a Jasco J-815 CD spectrophotometer (Jasco Analytical Instruments, Easton, MD) using a $1 \mathrm{~mm}$ path-length cylindrical quartz cuvette (Starna Cells Inc., Atascadero, CA). The spectra were recorded by scanning from 260 to $190 \mathrm{~nm}$ at a scan rate of $50 \mathrm{~nm} / \mathrm{min}$ with $1 \mathrm{~nm}$ step intervals. The final spectra recorded were an average of five scans with the ellipticity measured in millidegrees. The data was corrected for the solvent, and the spectra were smoothed using a Savitsky-Golay filter on the Spectra Analysis software provided by the manufacturer (Jasco Inc., Easton, MD).

Thermogravimetric Analysis (TGA). The thermal analysis of the AuNPs with peptides was carried out using a TGA50, Shimzadu thermogravimetric analyzer (Shimzadu Corp., Kyoto, Japan) by increasing the temperature from 25 to 800 ${ }^{\circ} \mathrm{C}$ at the rate of $5{ }^{\circ} \mathrm{C} / \mathrm{min}$ and nitrogen gas flow rate of 10 $\mathrm{mL} / \mathrm{min}$.

\section{ASSOCIATED CONTENT}

\section{Supporting Information}

The Supporting Information is available free of charge on the ACS Publications website at DOI: 10.1021/acsomega.8b01633.

Schematic model for BAP-AuNP synthesis; dynamic light scattering data and NMR analyses; MALDI-TOF mass spectra of peptides (PDF)

\section{AUTHOR INFORMATION}

\section{Corresponding Author}

*E-mail: jtomich@ksu.edu.

ORCID $\odot$

Pavithra Natarajan: 0000-0003-3478-2293

Pinakin Sukthankar: 0000-0002-9043-5846

John M. Tomich: 0000-0001-7848-8307

Present Address

${ }^{\perp}$ Department of Molecular Biosciences, University of Kansas, Lawrence, Kansas 66045, United States (P.S.).

\section{Author Contributions}

The manuscript was written through contributions of all authors. All authors have given approval to the final version of the manuscript.

Funding

Partial support for this project was provided by Kansas State University Research Foundation, the Terry Johnson Cancer Center Innovation award (J.M.T.), and by the USDA's National Institute of Food and Agriculture through the Specialty Crops Research Initiative/Citrus Disease Research \& Extension, USDA NIFA Award No. 2015-70016-23028. Partial support was received through the Graduate Student Summer Stipend Award for Summer 2017 by Johnson Cancer Research Center, Kansas State University.

\section{Notes}

The authors declare no competing financial interest.

\section{ACKNOWLEDGMENTS}

This is publication 19-005-J from the Kansas Agricultural Experiment Station. The work carried out in this project was initiated by P.S. but greatly expanded upon and completed by P.N. Without the careful early studies, this project would not have succeeded. We would like to thank S. Bosman at the Department of Chemistry, Kansas State University for helping with the thermogravimetric analysis and $S$. Whitaker for synthesizing the peptides for our study. We would also like to thank the NMR Center at UNL and Maria Gonzalez, the Biological Science Technician at the Electron Microscope Facility in USDA, ARS, U.S. Horticultural Research Lab, Fort Pierce, FL 34945. C.S.H. was working under The ARS Research Participation Program (ARS-RPP), Oak Ridge Institute for Science and Education (ORISE). The publication of this article was funded in part by the Kansas State University Open Access Publishing Fund (KOAPF).

\section{ABBREVIATIONS}

BAPs, branched amphiphilic peptides; BAPCs, branched amphiphilic peptide capsules; AuNPs, gold nanoparticles; TEM, transmission electron microscopy; EDX, energydispersive X-ray; $\mathrm{Phe}_{\mathrm{CN}}$, cyanophenylalanine; LSPR, localized surface plasmon resonance; UV-vis, ultraviolet-visible; NPs, 
nanoparticles; TGA, thermogravimetric analysis; FRET, Förster resonance energy transfer; TFA, trifluoroacetic acid; TFE, trifluoroethanol; MNBs, magnetic nanobeads; CD, circular dichroism

\section{REFERENCES}

(1) Barros, S. M.; Whitaker, S. K.; Sukthankar, P.; Avila, L. A.; Gudlur, S.; Warner, M.; Beltrão, E. I. C.; Tomich, J. M. A Review of Solute Encapsulating Nanoparticles Used as Delivery Systems with Emphasis on Branched Amphipathic Peptide Capsules. Arch. Biochem. Biophys. 2016, 22-42.

(2) Gudlur, S.; Sukthankar, P.; Gao, J.; Avila, L. A.; Hiromasa, Y.; Chen, J.; Iwamoto, T.; Tomich, J. M. Peptide Nanovesicles Formed by The Self-Assembly of Branched Amphiphilic Peptides. PLoS One 2012, 7, No. e45374.

(3) Sukthankar, P.; Gudlur, S.; Avila, L. A.; Whitaker, S. K.; Katz, B. B.; Hiromasa, Y.; Gao, J.; Thapa, P.; Moore, D.; Iwamoto, T.; Chen, J.; Tomich, J. M. Branched Oligopeptides form Nanocapsules with Lipid Vesicle Characteristics. Langmuir 2013, 29, 14648-14654.

(4) Sukthankar, P.; Whitaker, S. K.; Garcia, M.; Herrera, A.; Boatwright, M.; Prakash, O.; Tomich, J. M. Thermally Induced Conformational Transitions in Nascent Branched Amphiphilic Peptide Capsules. Langmuir 2015, 31, 2946-2955.

(5) Barros, S. M.; Avila, L. A.; Whitaker, S. K.; Wilkinson, K. E.; Sukthankar, P.; Beltrão, E. I.; Tomich, J. M. Branched Amphipathic Peptide Capsules: Different Ratios of the Two Constituent Peptides Direct Distinct Bilayer Structures, Sizes, and DNA Transfection Efficiency. Langmuir 2017, 33, 7096-7104.

(6) Liang, X.; Shi, B.; Wang, K.; Fan, M.; Jiao, D.; Ao, J.; Song, N.; Wang, C.; Gu, J.; Li, Z. Development of Self-Assembling Peptide Nanovesicle with Bilayers for Enhanced EGFR-Targeted Drug and Gene Delivery. Biomaterials 2016, 82, 194-207.

(7) Li, S.; Mehta, A. K.; Sidorov, A. N.; Orlando, T. M.; Jiang, Z.; Anthony, N. R.; Lynn, D. G. Design of Asymmetric Peptide Bilayer Membranes. J. Am. Chem. Soc. 2016, 138, 3579-3586.

(8) Fatouros, D. G.; Lamprou, D. A.; Urquhart, A. J.; Yannopoulos, S. N.; Vizirianakis, I. S.; Zhang, S.; Koutsopoulos, S. Lipid-like SelfAssembling Peptide Nanovesicles for Drug Delivery. ACS Appl. Mater. Interfaces 2014, 6, 8184-8189.

(9) Homberger, M.; Simon, U. On the Application Potential of Gold Nanoparticles in Nanoelectronics and Biomedicine. Philos. Trans. $R$. Soc., A 2010, 368, 1405-1453.

(10) Kalimuthu, K.; Lubin, B.; Bazylevich, A.; Gellerman, G.; Shpilberg, O.; Luboshits, G.; Firer, M. A. Gold nanoparticles stabilize peptide-drug-conjugates for sustained targeted drug delivery to cancer cells. J. Nanobiotechnol. 2018, 16, 34.

(11) Dykman, L.; Khlebtsov, N. Gold Nanoparticles in Biomedical Applications: Recent Advances and Perspectives. Chem. Soc. Rev. 2012, 41, 2256-2282.

(12) Vilela, D.; González, M. C.; Escarpa, A. Sensing Colorimetric Approaches Based on Gold and Silver Nanoparticles Aggregation: Chemical Creativity Behind The Assay. A Review. Anal. Chim. Acta 2012, 751, 24-43.

(13) Xia, F.; Zuo, X.; Yang, R.; Xiao, Y.; Kang, D.; Vallee-Belisle, A.; Gong, X.; Hsu, B. B.; Yuen, J. D.; Heeger, A. J.; Plaxco, K. W. Colorimetric detection of DNA, small molecules, proteins, and ions using unmodified gold nanoparticles and conjugated polyelectrolytes. Proc. Natl. Acad. Sci. U.S.A. 2010, 107, 10837-10841.

(14) Valentini, P.; Pompa, P. P. Gold nanoparticles for naked-eye DNA detection: Smart designs for sensitive assays. RSC Adv. 2013, 3, 19181.

(15) Brust, M.; Walker, M.; Bethell, D.; Schiffrin, D. J.; Whyman, R. Synthesis of Thiol-Derivatised Gold Nanoparticles in a Two-Phase Liquid-Liquid System. J. Chem. Soc., Chem. Commun. 1994, 801802.

(16) Turkevich, J.; Stevenson, P. C.; Hillier, J. A Study of the Nucleation and Growth Processes In the Synthesis Of Colloidal Gold. Discuss. Faraday Soc. 1951, 11, 55.
(17) Lin, X. M.; Sorensen, C. M.; Klabunde, K. J. Digestive Ripening, Nanophase Segregation and Superlattice Formation In Gold Nanocrystal Colloids. J. Nanopart. Res. 2000, 2, 157-164.

(18) Piella, J.; Bastús, N. G.; Puntes, V. Size-Controlled Synthesis of Sub-10-nanometer Citrate-Stabilized Gold Nanoparticles and Related Optical Properties. Chem. Mater. 2016, 28, 1066-1075.

(19) Serizawa, T.; Hirai, Y.; Aizawa, M. Novel Synthetic Route to Peptide-Capped Gold Nanoparticles. Langmuir 2009, 25, 1222912234.

(20) Karki, I.; Wang, H.; Geise, N. R.; Wilson, B. W.; Lewis, J. P.; Gullion, T. Tripeptides on Gold Nanoparticles: Structural Differences Between Two Reverse Sequences As Determined by Solid-State NMR and DFT Calculations. J. Phys. Chem. B 2015, 119, 11998-12006.

(21) Love, J. C.; Estroff, L. A.; Kriebel, J. K.; Nuzzo, R. G.; Whitesides, G. M. Self-Assembled Monolayers of Thiolates on Metals As a Form of Nanotechnology. Chem. Rev. 2005, 105, 1103-1170.

(22) Xue, Y.; Li, X.; Li, H.; Zhang, W. Quantifying Thiol-Gold Interactions Towards the Efficient Strength Control. Nat. Commun. 2014, 5, No. 4348.

(23) Schneider, G.; Decher, G.; Nerambourg, N.; Praho, R.; Werts, M. H.; Blanchard-Desce, M. Distance-Dependent Fluorescence Quenching on Gold Nanoparticles Ensheathed with Layer-by-Layer Assembled Polyelectrolytes. Nano Lett. 2006, 6, 530-536.

(24) Reddy, L. H.; Arias, J. L.; Nicolas, J.; Couvreur, P. Magnetic Nanoparticles: Design and Characterization, Toxicity and Biocompatibility, Pharmaceutical and Biomedical Applications. Chem. Rev. 2012, $112,5818-5878$.

(25) Amiri, S.; Shokrollahi, H. The role of cobalt ferrite magnetic nanoparticles in medical science. Mater. Sci. Eng., C 2013, 33, $1-8$.

(26) Silva, S. M.; Tavallaie, R.; Sandiford, L.; Tilley, R. D.; Gooding, J. J. Gold Coated Magnetic Nanoparticles: From Preparation to Surface Modification for Analytical and Biomedical Applications. Chem. Commun. 2016, 52, 7528-7540.

(27) Avila, L. A.; Chandrashekar, R.; Wilkinson, K. E.; Balthazor, J.; Heerman, M.; Brown, S.; Dhar, S.; Bechard, J.; Park, Y.; Reeck, G. R.; Tomich, J. M. Delivery of lethal dsRNA in insect diets by branched amphiphilic peptide capsules. J. Controlled Release 2018, 273, 139146.

(28) Avila, L.; Aps, L.; Ploscariu, N.; Sukthankar, P.; Guo, R.; Wilkinson, K.; Games, P.; Szoszkiewicz, R.; Alves, R. P. Z.; Diniz, M.; et al. Gene Delivery and Immunomodulatory Effects of Plasmid DNA Associated with Branched Amphiphilic Peptide Capsules. J. Controlled Release 2016, 241, 15-24.

(29) Rasband, W. S. ImageJ; U.S. National Institutes of Health: Bethesda, MD, https://imagej.nih.gov/ij/, 1997-2018.

(30) Liu, X.; Atwater, M.; Wang, J.; Huo, Q. Extinction coefficient of gold nanoparticles with different sizes and different capping ligands. Colloids Surf., B 2007, 58, 3-7.

(31) Han, X.; Goebl, J.; Lu, Z.; Yin, Y. Role of Salt in the Spontaneous Assembly of Charged Gold Nanoparticles in Ethanol. Langmuir 2011, 27, 5282-5289.

(32) Andrushchenko, V. V.; Vogel, H. J.; Prenner, E. J. Optimization of The Hydrochloric Acid Concentration Used for Trifluoroacetate Removal from Synthetic Peptides. J. Pept. Sci. 2007, 13, 37-43.

(33) Glasscock, J. M.; Zhu, Y.; Chowdhury, P.; Tang, J.; Gai, F. Using an Amino Acid Fluorescence Resonance Energy Transfer Pair to Probe Protein Unfolding: Application to the Villin Headpiece Subdomain and the LysM Domain. Biochemistry 2008, 47, 1107011076.

(34) Tucker, M. J.; Oyola, R.; Gai, F. Conformational Distribution of a 14-Residue Peptide in Solution: A Fluorescence Resonance Energy Transfer Study. J. Phys. Chem. B 2005, 109, 4788-4795.

(35) Jia, Z.; Whitaker, S. K.; Tomich, J. M.; Chen, J. Organization and Structure of Branched Amphipathic Oligopeptide Bilayers. Langmuir 2016, 32, 9883-9891.

(36) Cao, Y.; Mu, T. Comprehensive Investigation on the Thermal Stability of 66 Ionic Liquids by Thermogravimetric Analysis. Ind. Eng. Chem. Res. 2014, 53, 8651-8664. 
(37) Dunn, M. S.; Brophy, T. W. Decomposition Points of Amino Acids. J. Biol. Chem. 1932, 99, 221-229.

(38) Rogers, J. M.; Lippert, L. G.; Gai, F. Non-natural amino acid fluorophores for one- and two-step fluorescence resonance energy transfer applications. Anal. Biochem. 2010, 399, 182-189.

(39) Goldys, E. M.; Sobhan, M. A. Gold Nanoparticles: Fluorescence of Colloidal Gold Nanoparticles is Controlled by the Surface Adsorbate. Adv. Funct. Mater. 2012, 22, 1989.

(40) Lopez-Chaves, C.; Soto-Alvaredo, J.; Montes-Bayon, M.; Bettmer, J.; Llopis, J.; Sanchez-Gonzalez, C. Gold nanoparticles: Distribution, bioaccumulation and toxicity. In vitro and in vivo studies. Nanomedicine 2018, 14, 1-12.

(41) Alba-Tercedor, J.; Hunter, W. B.; Cicero, J. M.; Bariain, M. S.; Brown, S. J. In Use of Micro-CT to Elucidate Details of the Anatomy and Feeding of the Asian Citrus Psyllid Diaphorina Citri Kuwayama, 1908 (Insecta: Hemiptera, Liviidae), Micro-CT User Meeting 2017; Royal Belgian Institute of Natural Science: Brussels, 2017; pp 270-285. 